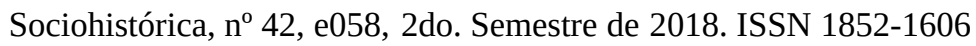

Universidad Nacional de La Plata.

Facultad de Humanidades y Ciencias de la Educación.

Centro de Investigaciones Socio Históricas

\title{
La lucha de las organizaciones de trabajadores desocupados en los últimos años del kirchnerismo. Análisis del proceso de protesta ligado al Programa "Argentina Trabaja"
}

María Maneiro

CONICET - Programa de Conflicto Social, Instituto de Investigaciones "Gino Germani", Facultad de Ciencias Sociales, Universidad de Buenos Aires (IIGG, FSOC, UBA), Argentina mariamaneiropinhero@gmail.com

Cita recomendada: Maneiro, M. (2018). La lucha de las organizaciones de trabajadores desocupados en los últimos años del kirchnerismo. Análisis del proceso de protesta ligado al Programa "Argentina Trabaja". Sociohistórica, 42, e058. https://doi.org/10.24215/18521606e058

Recibido: 12 diciembre 2017 - Aceptado: 07 mayo 2018 - Publicado: 3 diciembre 2018 


\section{La lucha de las organizaciones de trabajadores desocupados en los últimos años del kirchnerismo. Análisis del proceso de protesta ligado al Programa "Argentina Trabaja"}

The struggle of the unemployed workers' organizations in the last years of kirchnerism Analysis of the protest process linked to the "Argentina Trabaja" Program

María Maneiro

CONICET - Programa de Conflicto Social, Instituto de

Investigaciones "Gino Germani", Facultad de Ciencias

Sociales, Universidad de Buenos Aires (IIGG, FSOC,

$U B A$ ), Argentina

mariamaneiropinhero@gmail.com

\section{Resumen:}

Este artículo se propone reintroducir el estudio acerca de las acciones de lucha de las organizaciones de trabajadores desocupados en los últimos años del kirchnerismo. El análisis de este proceso se sitúa en la demanda de inclusión y de actualización de los montos del Programa Ingreso Social con Trabajo "Argentina Trabaja". Con ello se busca promover una actualización reflexiva y una revisión empírica de los estudios sobre la acción colectiva de los trabajadores desocupados. Para ello se propone un abordaje que describa y analice el proceso de lucha. Este se describe a partir de sus formatos de acción, sus demandas y las principales organizaciones participantes, como así también las interacciones que se producen. El soporte empírico comprende una base de datos de 307 acciones construida a partir de las noticias publicadas en los medios nacionales y locales referentes a la lucha en torno al Programa "Argentina Trabaja". El recorte temporal se encuentra entre septiembre de 2009 y junio 2012. Como sostén auxiliar se utiliza una serie de entrevistas a referentes y militantes de base del Frente Popular Darío Santillán. El proceso de confrontación estudiado permite conocer un nuevo momento en relación a la lucha de las organizaciones de trabajadores desocupados. En este las organizaciones de base territorial, que inician la lucha, van quedando debilitadas y asociadas a las iniciativas de las organizaciones insertas en las líneas sindicales y/o partidarias.

Palabras clave: Organizaciones sociales, Trabajadores desocupados, Movimiento piquetero, Conflicto social, Programa Ingreso social con Trabajo Argentina Trabaja.

\section{Abstract:}

This article aims at reintroducing the study of the unemployed workers' organizations struggle in the last years of kirchnermism. Thisanalysis focuses in the demand for accessing and updating of the amounts pertaining to the ProgramaIngreso Social con Trabajo (Social Income through Labour Programme) referred to as Argentina Trabaja (Argentina Works). This paper seeks a reflexive update and an empirical review of the studies regarding the collective action of unemployed. On the basis of such a goal, an approach is proposed which describes and analyzes the struggle process of social movements. As regards action formats, their demands and their main organizations, as well as their interactions. The empirical basis encompasses a database of 307 actions built upon news published in national and local media regarding the struggle surrounding the Argentina Trabaja Programme. The time frame ranges from September 2009 to June 2012. As ancillary support we use a series of interviews to role models and grassroot activists of Frente Popular DaríoSantillán. The confrontation process studied makes it possible to show a new moment in relation to the unemployed workers' organizations. During this process the territorial grassroot groups who started the struggle, at a subsequent moment, became weaker and needed to link to the initiatives of trade-union or party organizations.

KeYwords: Social organizations, Piquetero movement, Social conflict, Social protest, Income through Labour Programme Argentina works (Programaingreso social con trabajo Argentina Trabaja). 


\section{A MODO DE INTRODUCCIÓN}

A pesar de que el campo de estudios en torno al conflicto social tiene larga data en nuestro campo académico, para mediados de la década de los 90 en el contexto de un aumento exponencial del desempleo y de una crisis de los anclajes de integración política, la emergencia de colectividades beligerantes demandantes de empleo abrió paso a un nuevo momento en las investigaciones acerca del conflicto social. Nos referimos con ello a los trabajos que han aparecido en el campo de las ciencias sociales bajo el paraguas temático de la protesta y que refieren a las descripciones, las interpretaciones y el análisis del ciclo de acción colectiva, cuya expresión sobresaliente se encuentra en los sucesos de fines de diciembre del año 2001 y el extraordinario año $2002 .{ }^{1} \mathrm{Un}$ cuerpo significativo de estos estudios abordó la sociogénesis y el desarrollo de los movimientos de trabajadores desocupados, sus vertientes y sus formatos de lucha, como así también sus modalidades de organización.

El devenir de estas organizaciones durante los gobiernos kirchneristas, sin embargo, no fue estudiado con similar profusión. Mientras algunos investigadores lo exploraron desde las tramas de interacción local, otros situaron sus preocupaciones en las formas de inclusión de los referentes dentro las diversas instancias del gobierno del Estado. No obstante, la acción colectiva de carácter demandante de estos grupos no se desvaneció y reapareció con relevancia ante el anuncio del Programa de Ingreso Social con Trabajo. Argentina Trabaja (PRIST) en agosto de 2009.

El objetivo general de este trabajo es conocer el proceso de lucha llevado adelante por las organizaciones sociales en torno a la inclusión dentro de este programa y a la resolución de demandas relativas a la ejecución del mismo. Los interrogantes que guían este trabajo son: quiénes protestan en este período, con quiénes se vinculan, cuáles son los formatos de acción que utilizan y qué demandas poseen. La exploración de estas variables, como aspectos clásicos de un estudio sobre acciones de lucha, posibilitará actualizar el campo de investigación sobre la protesta en general y sobre la acción de confrontación de las organizaciones de trabajadores desocupados en particular, que tan fértil fue en momentos previos.

Los datos construidos tuvieron como fuente primordial el universo de noticias aparecidas en el diario Clarín $^{2}$-en su edición digital- entre septiembre de 2009 y junio de 2012; el comienzo y el final de la serie se justifican por el inicio y la merma de las acciones relativas a nuestro objeto de estudio. Con el fin de enriquecer la base de datos, dentro de este corpus se adicionaron los datos provenientes de las cronologías de conflictividad social elaboradas por el Observatorio Social de América Latina del Consejo Latinoamericano de Ciencias Sociales (CLACSO) para la Argentina - con el fundamento de que esta base de datos posee una mayor cobertura federal-; por último, aquellas acciones cuya referencia era limitada fueron exploradas en medios locales con el fin de completar el registro.

La definición de acción colectiva que guía este artículo retoma -selectivamente- sugerencias de Tilly Wood (2010). Estas poseen un carácter colectivo y suponen demandas cuyo destinatario y responsable respecto de la resolución del problema planteado es el gobierno del Estado -en sus diversas jurisdicciones-. Para este trabajo se ha tomado como unidad de análisis el evento de acción de lucha, desdoblando hechos simultáneos y/o secuenciales -lo cual supone un distanciamiento respecto del entendimiento de este como un sistema de acciones unificadas en la continuidad de decisiones de un mismo sujeto-. Para cada una de las 307 acciones se registró la fecha (día, mes y año), el lugar (nombre de la ciudad, municipio y provincia), el formato de la acción (a partir de una codificación inductiva), la densidad (registra si se inserta en hechos que la contienen), el/los sujeto/s de la acción (el nombre de la organización o de las organizaciones que realizan la acción), la/s demanda/s explícita/s, el/los destinatario/s (que siempre, por definición, incluían al Estado), la duración (en cantidad de horas) y el/los aliado/s (la red de solidaridades a la que se alude).

El supuesto que se liga con la construcción del recorte temporal de esta investigación está centrado en la interpretación de este proceso como un ciclo de acción contenciosa, que a su vez, como se expondrá a posteriori, se compone de dos momentos diferentes. La noción de ciclo de acción de lucha fue trabajada por Tarrow (1987) y remite a un proceso cuya distribución de frecuencias de acciones colectivas podría ser 
representada por una parábola. En nuestro estudio el primer momento de este proceso posee una dinámica cuya representación se asemeja a la parábola que menciona Tarrow, mientras el segundo momento evidencia serruchos significativos. Los ciclos de acción colectiva que estudia el autor comprenden una serie de rasgos característicos, y algunos de ellos pueden encontrarse en nuestro estudio, a saber: una secuencia caracterizada por un nivel de conflicto que excede el considerado "normal" para esa sociedad, una rápida difusión territorial y organizacional, una aceleración en el ritmo de las interacciones, etc. ${ }^{3}$ El estudio de las interacciones no resulta simple y, por cuestiones de plausibilidad, en este trabajo se ha centrado la atención en las relaciones que las organizaciones establecen con cuatro organizaciones que asumen mayor protagonismo en el proceso investigado.

El trabajo que se presenta en este artículo se enmarca en un proyecto amplio ${ }^{4}$ que incluye variadas modalidades de construcción de los datos. Por ello, además del registro periodístico, se realizaron entrevistas en profundidad en dos cooperativas del Movimiento de Trabajadores Desocupados "Javier Barrionuevo" que pertenece al Frente Popular Darío Santillán. Este material se incluyó de manera auxiliar para dotar de palabras a los sujetos de la acción que conforman las redes de las organizaciones territoriales -cuyas acciones poseen menor primacía en los medios de comunicación-; en nuestra experiencia, a su vez, una escucha atenta de sus dichos posibilitó la construcción de itinerarios de exploración e hipótesis de trabajo que se desarrollan en el presente artículo; un elemento ético, entonces, que subraya la co-construcción colectiva de muchos de los interrogantes que se intentan responder en este artículo, sostiene el fundamento de la inclusión de estos entrevistados.

\section{LAS ORGANIZACIONES DE TRABAJADORES DESOCUPADOS Y SU EMERGENCIA PÚBLICA}

La emergencia de colectividades articuladas en torno a la demanda de "empleo" con asiento territorial fue ampliamente estudiada por la academia. Una serie de trabajos pusieron el acento en la sociogénesis, el desarrollo y las potencias de estos movimientos. El trabajo canónico acerca de esta cuestión es el de Svampa y Pereyra (2003); ellos identifican, dentro de las organizaciones surgidas en el conurbano, tres líneas diferenciales: la línea sindical, la línea política y la línea territorial. ${ }^{5}$ Rememoraremos esta diferenciación para repensar las formas de agregación de las organizaciones que emergen en el conflicto que analizamos en este artículo.

En torno a la línea sindical, los autores citados describen un eje de aglomeración que tiene un fuerte asiento en La Matanza pero que conforma una expresión nacional, en cuya matriz se encuentra la Federación de Tierras y Viviendas (FTV) y la Corriente Clasista y Combativa (CCC); la primera constituye un agrupamiento de organizaciones de base territorial ${ }^{6}$ insertas en la Central de Trabajadores Argentinos (CTA) y la segunda nuclea la rama sindical del Partido Comunista Revolucionario (PCR). Dentro de la FTV confluían dos organizaciones ligadas a partidos políticos, la CTA de los Barrios, que luego se llamaría Barrios de Pie (BdP), vinculada a la Corriente Patria Libre, y el Movimiento Territorial de Liberación (MTL) articulado al Partido Comunista (PC). Estas últimas organizaciones se separarían de este eje durante la crisis de $2001 .^{7}$

La segunda línea que diferencian Svampa y Pereyra incluye a las organizaciones de trabajadores desocupados ligadas a los partidos políticos de izquierda y a las organizaciones político-sociales vinculadas a la matriz marxista. Entre ellas se pueden destacar el Polo Obrero (PO), perteneciente al Partido Obrero (PO), el Movimiento Sin Trabajo “Teresa Vive” (MST) ligado al Movimiento Socialista de los Trabajadores (MST), y la Coordinadora de Unidad Barrial (CUBa) vinculada al Partido Revolucionario (Marxista-leninista). Dentro de esta misma línea los autores incluyen al Movimiento Teresa Rodríguez (MTR), pionero en la génesis de las organizaciones de trabajadores desocupados en la zona sur del conurbano y en Mar del Plata. Estos grupos confluyeron durante la crisis en una articulación llamada Bloque Piquetero. 
La tercera línea está compuesta por organizaciones locales de base territorial, muchas de ellas microorganizaciones, asentadas en los Movimientos de Trabajadores Desocupados (MTDs) de los diferentes municipios del Gran Buenos Aires. Estos MDTs poseían matrices ideológicas e identitarias disímiles a su interior; en un trabajo previo (2012) resaltamos tres emergentes: una vinculada a lo nacional y popular de Lanús y Glew, una segunda autonomista en Solano y una tercera nacionalista revolucionaria en La Plata. Todas ellas se articularon durante la crisis en la Coordinadora Aníbal Verón. Más allá de sus diversidades ideológicas, estas organizaciones se caracterizaron, entonces, por estar más desancladas tanto de las corrientes sindicales masivas como de los partidos políticos, mientras sobresalía entre sus características una impronta socioespacial.

El presente trabajo pretende retomar esta clasificación e interrogarse acerca de cuáles son las relaciones que las organizaciones actuales presentan. No obstante antes de abordar este aspecto es importante continuar con otras precisiones de la bibliografía de referencia.

La mirada en torno a la protesta social en general y a la productividad de la acción piquetera fue generando investigaciones acerca de las capacidades de sociabilidad de estas experiencias, la democratización de los microterritorios que abarcaban y la reconstrucción positivizante de las mismas (Retamozo, 2006; Svampa y Pereyra, 2003). La doble impronta local y extra local, cotidiana y extra cotidiana de estas organizaciones fue dando paso a trabajos que abordaban las interacciones microterritoriales en las que se desarrollaban las tramas locales y la acción colectiva: sus formatos, demandas, espacios, etc. ${ }^{8}$ Asimismo, hubo trabajos que atendieron a la relevancia de la movilización como nudo de construcción de sociabilidad y salida del entrampamiento barrial (Massetti, 2004).

Sin embargo, pocos años después, con la mutación del contexto político y económico y constatándose una mayor modularidad respecto de las acciones de bloqueo de vías públicas, las interrogaciones sobre la acción beligerante quedaron ligadas a la indagación acerca de las huellas que estas iniciativas han dejado (Pereyra, Pérez, y Schuster, 2008).

El proceso de eclipse de la acción colectiva y la fragmentación de las organizaciones de trabajadores desocupados se manifestaba, dentro de la producción académica, en la disminución de la productividad acerca de los estudios de las protestas relativas a las organizaciones de trabajadores desocupados. Empero, su eclipse en el espacio público no produjo una debacle respecto de los estudios sobre las tramas locales de relaciones sociales en las cuales se insertan las organizaciones sociales dentro de una madeja que las trasciende (Quirós, 2008; Manzano, 2009; Ferraudi Curto, 2014).

Cabe decir, también, que a pesar de este relativo eclipse respecto de la acción colectiva demandante se abrió una nueva serie de estudios que se ocuparon de las modalidades de inclusión de los movimientos de desocupados -y/o de sus referentes más conocidos- en las instituciones estatales (Pérez \& Natalucci, 2012) como así también respecto de las formas en que estos referentes desarrollan sus actividades en el seno burocrático (Perelmiter, 2016). En la bisagra entre estas dos modalidades de aproximación la experiencia de algunas organizaciones de trabajadores desocupados fue retematizada en su papel de organizador territorial y soporte - movilizatorio- de gobierno del Estado.

Sin embargo la acción de otras organizaciones más desancladas respecto del gobierno del Estado fue desdibujándose de los trabajos académicos. Sensibles a la centralidad de estudiar no sólo a los momentos de visibilidad sino también a los de latencia de las organizaciones sociales (Melucci, 1999), continuamos con la temática. Estudiando ese período de relativa invisibilidad de las organizaciones piqueteras encontramos una desligazón entre las dos vías de la acción de las organizaciones: la ruta y el barrio (Maneiro, 2009; Maneiro, Farías, \& Santana, 2009) dentro de un proceso general de retracción de la acción de lucha de calles de las fracciones trabajadoras desocupadas.

Sin embargo, desde mediados de 2009 se produce un nuevo ciclo de acción contenciosa -modesto pero no desdeñable- que merece ser atendido. Es este el proceso que exploraremos en este artículo. No obstante, antes de entrar en él, resulta relevante mencionar que el período estudiado presenta elementos contextuales 
que deben explicitarse. Durante el año 2008 -en el marco de un cuello de botella para poder continuar financiando la expansión económica- se desata un conflicto entre el gobierno nacional del Estado y las cuatro organizaciones patronales del sector agroganadero, pues estas últimas se oponen a la modificación en torno a las retenciones a la exportación de los productos agropecuarios; este conflicto genera una fuerte polarización política que se extiende temporalmente, hasta que el gobierno debe volver atrás con la propuesta. En este conflicto, a su vez, se expresa una oposición entre la mayor corporación mediática ${ }^{10}$ y el gobierno nacional; dicha oposición se fortifica al año siguiente con la aprobación parlamentaria de una nueva ley de servicios audiovisuales que restringe la posibilidad de monopolios en los medios de comunicación.

\section{LA ACCIÓN COLECTIVA Y LOS PROGRAMAS SOCIALES}

Es sabido que desde mediados de la década de los 90 la acción colectiva de las organizaciones de trabajadores desocupados se ha articulado a la demanda de ampliación y de gestión de programas sociales de "empleo". 1112 Cabe decir que la capacidad de gestión de programas sociales se vio favorecida durante el gobierno nacional de la Alianza (1999-2001) en el marco de una disputa con los mediadores territoriales del Partido Justicialista. No obstante, durante el año 2002, la magnitud y la modalidad organizativa del programa Jefes y Jefas de Hogar Desocupados produjo nuevos impactos en torno a la capacidad de gestión de programas de las organizaciones sociales. Una bifurcación entre quienes participaron de los consejos consultivos (la FTV y la CCC) y aquellos que permanecieron por fuera, marcó un antecedente respecto de las polarizaciones que abordaría la bibliografía durante el proceso político subsiguiente.

La gestión gubernamental de Néstor Kirchner (2003-2007) trajo consigo una nueva impronta estatal que interpeló a una serie de organizaciones sociales ligadas a la gramática nacional y popular. La rápida apertura del gobierno nacional respecto de una serie de organizaciones sociales y de derechos humanos tuvo un impacto central en las organizaciones de trabajadores desocupados.

La intervención política nacional acompañó y promocionó un ciclo de crecimiento económico financiado en el aumento del precio internacional de los productos agropecuarios (fundamentalmente la soja). Este proceso generó una reutilización de la capacidad productiva ociosa y un significativo aumento de la ocupación. Desde el gobierno del Estado se fomentó la valoración del estatuto del trabajo como modalidad de encastre social, ralentando la relevancia de los programas sociales clásicos. La importancia del programa Jefes y Jefas de Hogar desocupado se fue diluyendo y con sus remanentes se construyeron dos itinerarios: por un lado, el Programa Familias, que cobijó a aquellos con mayores dificultades de inserción en los mercados laborales; por otro lado, el Programa "Manos a la Obra", ${ }^{13}$ que no tuvo el peso cuantitativo que tendrían los anteriores, inauguró una nueva línea de articulación con las organizaciones sociales y se entroncó con la vertiente de fomento del cooperativismo y los microemprendimientos. ${ }^{14}$

Prontamente el mapeo de las líneas mencionadas previamente se vio trastocado. Muy resumidamente podemos cartografiar el espacio de las organizaciones de desocupados de la siguiente forma: la FTV, BdP y una serie de MTDs identificados con la matriz nacional y popular y/o con el nacionalismo revolucionario, se vieron interpelados con la propuesta proveniente del ejecutivo. Es así como se quiebra el tándem FTVCCC. La CCC va separándose paulatinamente, desde un primer momento de mayor cercanía hacia una oposición activa hacia el final del período que aborda este trabajo. En los primeros años del gobierno de Néstor Kirchner BdP se suma al entramado político oficial, y en ese contexto se acerca nuevamente a la FTV. Sin embargo, durante la presidencia de Cristina Kirchner - en el momento en que Néstor asume la presidencia del PJ-BdP vuelve a separarse del oficialismo y rápidamente se incluye en el arco opositor. Continuando con la gama de organizaciones que se ligan al kirchnerismo, el Movimiento Evita aglutina a aquellos grupos provenientes de la línea territorial. Cabe decir que el MTR se escinde en varias organizaciones diferentes, con disímiles niveles de acercamiento al gobierno nacional. Entre aquellos que no participan del entramado 
político oficial, en relación a la matriz territorial, se crea un nuevo eje de articulación bajo el nombre Frente Popular Darío Santillán que engloba a los movimientos restantes; no obstante muchas organizaciones locales continúan realizando acciones en forma independiente o de manera articulada pero sin formar parte organizada de una conglomeración más amplia. Las organizaciones vinculadas a los partidos trotskistas se mantuvieron claramente dentro de una estrategia de denuncia y oposición. ${ }^{15}$ Este proceso fue abordado desde la bibliografía académica enfatizando los senderos escindidos. Mientras una serie de organizaciones más vinculadas identitariamente a la matriz nacional y popular se fue insertando en espacios del gobierno del Estado; otras organizaciones, más ligadas a una identidad autonomista o marxista mantuvieron un vínculo con el gobierno del Estado mediado por la movilización demandante. ${ }^{16}$ Por situarse en un ámbito de reclamo público hacia el gobierno del Estado y bajo el recurso de la acción colectiva, en este trabajo se estudiará la segunda vertiente de estos dos itinerarios.

\section{El Programa Ingreso Social con Trabajo “Argentina Trabaja”}

Ya en el marco de la primera presidencia de Cristina Fernández de Kirchner, a mediados del mes de agosto de 2009, en un contexto de crisis política y desaceleración del crecimiento económico, insertándose dentro de una serie de medidas gubernamentales tendientes a la reducción de la pobreza, ${ }^{17}$ la presidente anuncia la implementación del Programa Ingreso Social con Trabajo, socialmente conocido como Plan "Argentina Trabaja" (PRIST). ${ }^{18}$

Este se rige oficialmente por la resolución 3182/09 y constituye uno de los programas sociales nacionales más significativos -en términos de recursos y alcance- de la primera gestión presidencial de Cristina Fernández de Kirchner (2007-2011). Dicho programa se orienta a grupos familiares cuyos adultos no cuenten con una pensión, jubilación o un programa social provincial incompatible y que no desarrollen una actividad económica registrada. A pesar de que el PRIST retoma elementos de planes anteriores, posee particularidades significativas. ${ }^{19}$ Una de ellas, de gran relevancia para sus partícipes, es que si sus precursores suponían un ingreso menor a 50 dólares mensuales -en el contexto de la licuación posdevaluatoria- en este el monto previsto al momento del anuncio del programa asciende a poco menos de 300 dólares. ${ }^{20}$ Otra de las características sobresalientes del programa, desde su marco normativo, es el fomento del "empleo" como fuente nodal de inclusión social, y de las "cooperativas" como modalidad explícita de organización local. ${ }^{21}$

Cabe decir que la implementación de este programa estuvo centralmente ligada a los entramados gubernamentales municipales; ${ }^{22}$ en muchos de ellos se constituyeron Unidades Ejecutoras para trabajar en la logística. En la intersección jurisdiccional se establecieron las prioridades de acción y se definieron los módulos de trabajo que se desarrollarían en cada territorio, los cuales ya tenían un menú prefijado. Las tareas de selección de los titulares, la conformación, el registro de las "cooperativas" y la firma de convenios interinstitucionales demoraron la puesta en marcha del trabajo.

A pocos días del anuncio del programa, una red de organizaciones sociales -de raigambre territorialdesligadas del entramado político oficial confluye en una serie de acciones de lucha que solicitan la apertura del padrón de beneficiarios y la autogestión del programa. En palabras de Andrés (un joven estudiante de 28 años que milita en el FPDS), ${ }^{23}$ este proceso emerge de la siguiente manera:

El gobierno nos quería dejar afuera de los planes "Argentina Trabaja” (...) y querían dejar afuera a las organizaciones que no pertenecían al peronismo "progresista”. Entonces nosotros (...) vimos que era necesario salir a luchar el tema de las cooperativas de trabajo, y que consigamos nuestra autonomía en cuanto a eso. Y bueno, así estuvimos un año y medio marchando a Desarrollo, al Puente, al Puente Pueyrredón, a un montón de lados, hubo un montón de trabas, hasta que bueno, llegamos a conseguir que nos anotaran en las cooperativas (Andrés-FPDS-, comunicación personal, 14 de septiembre, 2012) 
En las entrevistas que realizamos a los partícipes de este proceso de confrontación se expresa de manera enfática la defensa de un estatuto previamente conseguido, que remite a la participación activa en la gestión y distribución de programas sociales y de empleo.

Figura 1- Distribución de acciones de lucha en torno al

Programa Argentina Trabaja (Sep-2009- Junio 2012)

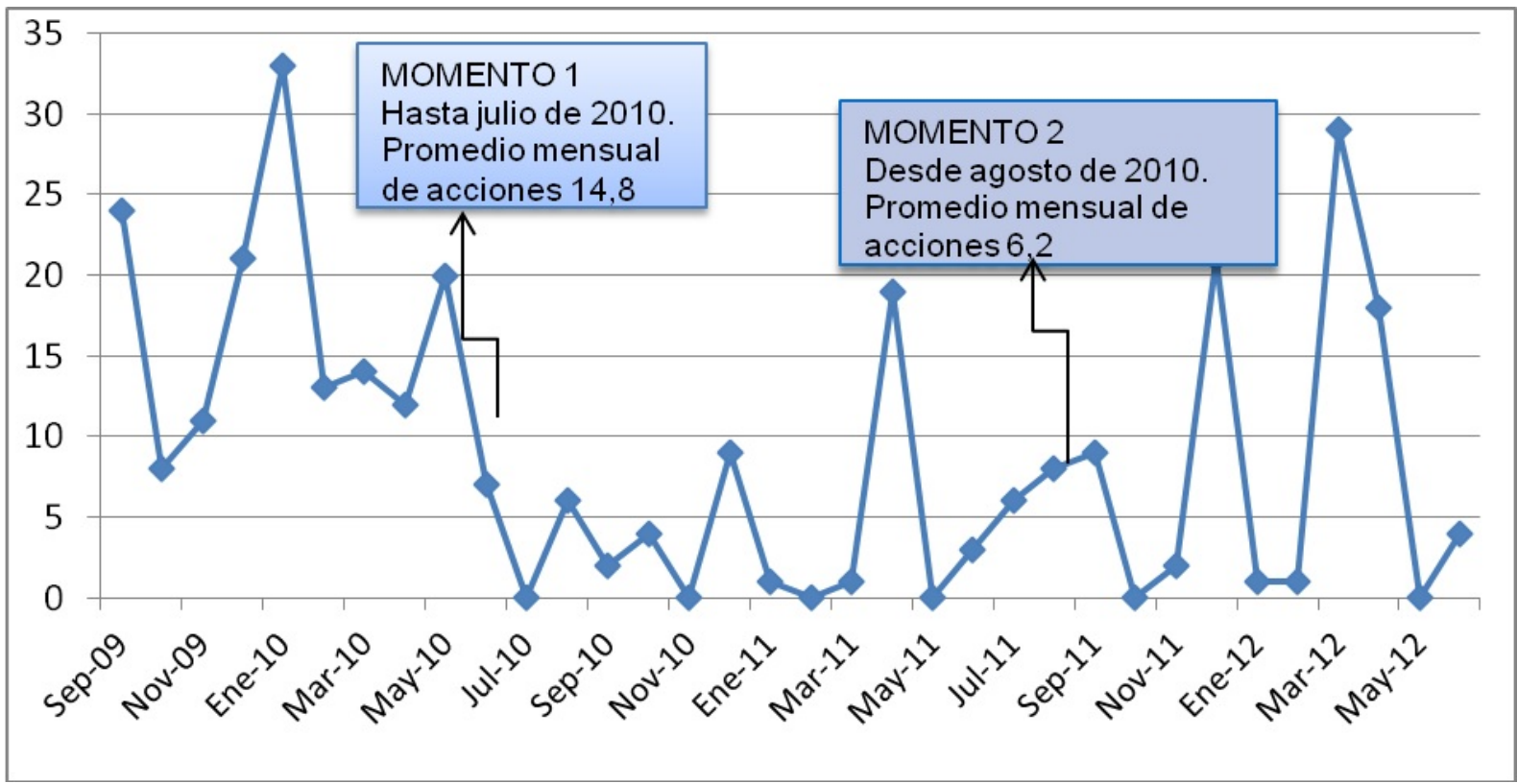

Fuente: PIP 11220110100563 Trabajo, redes territoriales y acción piquetera. El Impacto del Plan Argentina Trabaja (PRIST) en un movimiento de trabajadores desocupados del Gran Buenos Aires.

Tal como se puede ver en el gráfico 1, el proceso de confrontación que estamos analizando posee un diseño que nos permite hablar de dos momentos diferenciados. Describiremos aquí sintéticamente cada uno de estos para después profundizar en su especificidad.

El primer momento, más denso y corto, se desarrolla desde el anuncio del programa hasta julio de 2010 y construye una primera parábola que se asemeja al diseño clásico de un ciclo de protesta, aunque con serruchos relevantes: los momentos en los que se produce una frecuencia más alta de acciones son durante los meses de diciembre, enero y mayo. En el marco de procesos de confrontación, los meses climatológicamente más benévolos suelen mostrar una mayor frecuencia de acciones; el mes de diciembre -particularmente- se inscribe dentro de una memoria de acciones confrontativas y el mes de mayo, en el que se conmemoraba el bicentenario de la revolución de mayo, constituyó un centro de querella bajo la amenaza de las organizaciones de "teñir" la Fiesta del Bicentenario con un acampe por la demanda de ingreso en este programa social (Maneiro, 2015). Cabe decir, sin embargo, que la gran frecuencia de acciones durante el mes de enero constituye un elemento sorprendente; enero suele ser un mes de tregua y constituir un alto en relación a la acción de lucha, su excepción podría ser un indicador de la relevancia del proceso que estamos analizando.

El segundo momento, más extendido en el tiempo y con un menor promedio de acciones mensuales, remite a una configuración menos homogénea, en la cual sobresale no ya solamente la demanda de incorporación en el programa sino también el requerimiento de actualización del monto del ingreso mensual recibido por la participación en el programa; no obstante, las demandas previas no se desvanecen totalmente, sino que conforman un telón de fondo que se actualiza en forma recurrente. Este proceso de confrontación va densificándose poco a poco, aunque mostrando altibajos constantes y sin evidenciar una fortaleza de acciones comparable al primer momento señalado. 
Por último cabe decir que la red de organizaciones participantes en cada momento posee diferencias significativas; si bien en ambos momentos actúa una amplia gama de organizaciones, el primer momento posee un arco más extenso y heterogéneo, mientras que el segundo posee un núcleo más centralizado.

\title{
ANÁLISIS DEL PRIMER MOMENTO
}

Volvamos ahora al primer momento para profundizar su análisis. El reclamo en torno al ingreso en la gestión y distribución del programa no estuvo exento de tensiones. Durante el primer mes de acciones de lucha en el municipio de Esteban Echeverría, el 20 de noviembre de 2009, en una movilización hacia la municipalidad para reclamar la puesta en funcionamiento del programa bajo la gestión de las organizaciones sociales, se produjo una situación represiva que aparece reiteradamente en los relatos de los entrevistados. Alejandra, una cooperativista de 29 años de edad describe este episodio de la siguiente forma:

\begin{abstract}
El tema del reclamo es porque nosotros cuando luchamos por las cooperativas de trabajo, Argentina Trabaja, que las venimos luchando desde septiembre, fines de septiembre, del año pasado. A nosotros nos vienen diciendo que vamos a tener la posibilidad de entrar en este proyecto, pero no nos tienen en cuenta. Hace poco nos recibió el intendente, fueron unos compañeros, gestionaron un par de cosas, pero era como que no, no nos querían, nada, tuvimos una represión en Monte Grande, cuando fuimos a reclamar, nos reprimieron. Había gente con chicos, embarazadas, es como que también esto te va tirando un poco, hay compañeros que dicen, sí, ya está, no quiero saber más nada. Pero después te ponés a pensar y decís, no se pueden salir con la suya porque es algo que el pueblo se merece y tiene que ganárselo y es de cada uno.(Alejandra-FPDS-, comunicación personal, 12 de mayo, 2010). ${ }^{24}$
\end{abstract}

Alejandra describe la acción que constituye una de sus primeras protestas, y nos brinda otra perspectiva de los hechos a los cuales nos referimos. Sus historias, detrás de las capuchas, y las formas en que se fundamentan sus reclamos quedan obturados o fuertemente reducidos en las noticias de los medios masivos de comunicación. Este evento, sin ir más lejos, aparece en una nota brevísima que describe la acción sólo como "incidentes en el centro de Monte Grande". Entendemos que la densidad que expresa este primer momento de confrontación tiene como aspecto significativo este proceso de tensión y de represión expresa o latente en los municipios. De hecho es a posteriori de este suceso que la frecuencia de acciones crece significativamente y que la red de organizaciones partícipes en las protestas se extiende, expandiéndose la cantidad de organizaciones locales. ${ }^{25}$

\section{A) Las demandas}

Comencemos a trabajar con las demandas. El reclamo que hemos señalado en torno al pedido de participación y a la crítica respecto de la modalidad de gestión de los programas sociales, como se puede ver en la Tabla 1, surge en la remisión a tres cuestiones: el pedido de inclusión en el programa, la denuncia acerca del uso "clientelar" ${ }^{26}$ del mismo ${ }^{27}$ y la demanda de nacionalización del programa. Estos requerimientos, han tenido centralidad en el primer período de lucha. Entre agosto de 2009 y julio de 2010 cada una de peticiones están presentes en más del 60\% de las acciones.

Las tres demandas, sin bien contienen especificidades, poseen un núcleo común que se halla en el requerimiento de ampliación de las redes y las espacialidades respecto de la gestión de la política social y la denuncia acerca de las formas actuales de mediación. 
TABLA 1:

Demandas de las acciones

\begin{tabular}{|l|r|r|l|l|l|l|r|}
\hline & $\begin{array}{l}\mathbf{8 -} \\
\mathbf{2 0 0 9} \text { I } \\
\mathbf{7 - 2 0 1 0}\end{array}$ & $\begin{array}{l}\text { \% } \\
\text { demanda } \\
\text { Período }\end{array}$ & $\begin{array}{l}\text { \% } \\
\text { accione } \\
\text { s }\end{array}$ & $\begin{array}{l}\mathbf{8 -} \\
\mathbf{2 0 1 0 / 6 -} \\
\mathbf{2 0 1 2}\end{array}$ & $\begin{array}{l}\text { \% } \\
\text { demanda } \\
\text { s }\end{array}$ & $\begin{array}{l}\text { \% } \\
\text { accione } \\
\text { s }\end{array}$ & Total \\
\hline Pedido de inclusión & 112 & 40,00 & 70,00 & 48 & 13,83 & 30,00 & $\mathbf{1 6 0}$ \\
\hline Denuncia por uso clientelar & 68 & 24,29 & 66,67 & 34 & 9,80 & 33,33 & $\mathbf{1 0 2}$ \\
\hline $\begin{array}{l}\text { Demanda de nacionalización } \\
\text { del programa }\end{array}$ & 67 & 23,93 & 60,91 & 43 & 12,39 & 39,09 & $\mathbf{1 1 0}$ \\
\hline $\begin{array}{l}\text { Reclamo de aumento de } \\
\text { "haber" }\end{array}$ & 4 & 1,43 & 3,10 & 125 & 36,02 & 96,90 & $\mathbf{1 2 9}$ \\
\hline Pedido de alimentos & 1 & 0,36 & 2,86 & 34 & 9,80 & 97,14 & $\mathbf{3 5}$ \\
\hline Otras demandas & 28 & 10,00 & 30,77 & 63 & 18,16 & 69,23 & $\mathbf{9 1}$ \\
\hline Total & $\mathbf{2 8 0}$ & $\mathbf{1 0 0 , 0 0}$ & & $\mathbf{3 4 7}$ & $\mathbf{1 0 0 , 0 0}$ & & $\mathbf{6 2 7}$ \\
\hline
\end{tabular}

Fuente: PIP 11220110100563 Trabajo, redes territoriales y acción piquetera. El Impacto del Plan Argentina Trabaja (PRIST) en un movimiento de trabajadores desocupados del Gran Buenos Aires

Casi con la misma relevancia que la denuncia en torno al uso clientelar del programa, se encuentra la demanda por la nacionalización del programa. Este reclamo se encuentra más presente en las acciones de lucha que se producen en el interior del país. Cabe decir, en referencia a esta cuestión, que el programa se instala de manera gradual en el interior del país. Durante los primeros meses se asienta en treinta y seis municipios de la provincia de Buenos Aires para extenderse a las provincias de Tucumán, La Rioja y Corrientes (Repetto, Boix, \& Fernández, 2011).

TABLA 2

Distribución de las acciones y acciones con demanda de nacionalización del programa según lugar de la acción (primer período)

\begin{tabular}{|l|r|r|r|r|r|}
\hline & $\begin{array}{c}\text { Total } \\
\text { acciones }\end{array}$ & \multicolumn{1}{c|}{$\%$} & $\begin{array}{c}\text { Demanda de } \\
\text { Nacionalización }\end{array}$ & \multicolumn{1}{c|}{$\%$} & \\
\hline $\begin{array}{l}\text { Área } \\
\text { metropolitana }\end{array}$ & 76 & 48,41 & 13 & 19,40 & \\
\hline Resto del pais & 81 & 51,59 & 54 & 80,60 & \\
\hline Total & $\mathbf{1 5 7}$ & $\mathbf{1 0 0 , 0 0}$ & $\mathbf{6 7}$ & $\mathbf{1 0 0 , 0 0}$ & \\
\hline
\end{tabular}

Fuente: PIP 11220110100563 Trabajo, redes territoriales y acción piquetera. El Impacto del Plan Argentina Trabaja (PRIST) en un movimiento de trabajadores desocupados del Gran Buenos

Aires. Nota: 157 acciones producidas durante el primer período con datos de lugar de la acción.

Con posterioridad, el programa se amplía a casi todo el territorio nacional; sin embargo, finalizado incluso el segundo semestre de 2011, no estaba implementado en Santa Fe, Jujuy, Córdoba y Catamarca (Argentina Trabaja, 2011). Santa Fe, y específicamente Rosario, se presenta luego de la zona metropolitana con la mayor frecuencia de acciones de protesta, habiéndose registrado 44 acciones, las cuales se distribuyen por mitades en ambos períodos analizados. Consideramos que ello explicaría la continuidad de la demanda a lo 
largo del tiempo y su inscripción específica, durante este segundo período, en acciones que se desarrollan particularmente en estos espacios sociales.

Queda ingresar en las demandas solicitadas según las diversas organizaciones. Para analizar las demandas hemos seleccionado las cuatro organizaciones más activas del ciclo, a saber: Barrios de Pie, Corriente Clasista y Combativa, Frente Popular Darío Santillán y Polo Obrero. ${ }^{28}$ La tabla que mostramos debe ser leída con precaución puesto que tanto las demandas como las organizaciones no constituyen categorías mutuamente excluyentes, es decir que en una misma acción pueden participar más de una organización, cada acción puede contener más de una demanda o, incluso, una misma demanda puede ser solicitada por más de una organización (como por ejemplo en este caso el pedido de alimentos). A pesar de estas advertencias, la tabla 3 nos permite mostrar la relevancia de las tres demandas mencionadas y asimismo su peso particular en cada una de las organizaciones.

TABLA 3

Distribución de las demandas en principales organizaciones (primer período)

\begin{tabular}{|l|r|r|r|r|r|r|r|c|}
\hline \multicolumn{1}{|c|}{ Demandas } & BdP & \multicolumn{1}{c|}{$\%$} & CCC & \multicolumn{1}{c|}{$\%$} & FPDS & $\%$ & PO & $\%$ \\
\hline Pedido de inclusión & 58 & 40,85 & 38 & 32,20 & 24 & 35,29 & 38 & 41,30 \\
\hline Denuncia por uso clientelar & 31 & 21,83 & 22 & 18,64 & 26 & 38,24 & 20 & 21,74 \\
\hline Demanda de nacionalización & 35 & 24,65 & 34 & 28,81 & 11 & 16,18 & 22 & 23,91 \\
\hline $\begin{array}{l}\text { Reclamo de aumento de } \\
\text { "haber" }\end{array}$ & 1 & 0,70 & 1 & 0,85 & 1 & 1,47 & 1 & 1,09 \\
\hline Pedido de alimentos & 0 & 0,00 & 1 & 0,85 & 1 & 1,47 & 0 & 0,00 \\
\hline Otras & 17 & 11,97 & 22 & 18,64 & 5 & 7,35 & 11 & 11,96 \\
\hline Total & 142 & 100,00 & 118 & 100,00 & 68 & 100,00 & 92 & 100,00 \\
\hline
\end{tabular}

Fuente: PIP 11220110100563 Trabajo, redes territoriales y acción piquetera. El Impacto del Plan Argentina Trabaja (PRIST) en un movimiento de trabajadores desocupados del Gran Buenos Aires

La tabla 3 nos permite diferenciar el peso de las diversas demandas en estas cuatro organizaciones. Lo que se destaca es la relevancia del pedido de inclusión como solicitud encarada por las cuatro organizaciones más participativas; no obstante es menester afirmar que en el FPDS esta demanda tiene un peso menor que la denuncia por uso clientelar. En torno a esta última, se puede ver que su relevancia se encuentra debilitada en relación a la tabla 1 , y esto nos permite afirmar que son las pequeñas organizaciones junto con el FPDS las que más enfatizan esta solicitud -de la mano con su característica territorial fuertemente anclada en las barriadas del Gran Buenos Aires-. En contrapunto con ello la demanda de nacionalización del programa posee mayor centralidad en las organizaciones más grandes de tipo partidarias y/o sindicales.

\section{B) Los formatos de acción}

Desde su génesis, las organizaciones de trabajadores desocupados estuvieron ligadas a un formato de acción colectiva que los ha identificado: los bloqueos de vías públicas. La bibliografía que estudió la génesis y el desarrollo de estas organizaciones enfatizó la articulación entre la existencia misma de estos grupos y esta herramienta de lucha, ${ }^{29}$ la nominación piqueteros por parte de sí mismos y de terceros sostuvo esta imbricación; sin embargo, los procesos de confrontación posteriores han evidenciado que este formato se constituyó en una herramienta modular utilizada por múltiples sujetos sociales. ${ }^{30}$ 
Cabe decir, sin embargo, que a casi quince años de los primeros cortes de ruta de los trabajadores desocupados, y después de un período de eclipse de sus acciones, en este nuevo proceso de confrontación los bloqueos de vías públicas vuelven a asumir centralidad. Tal como lo hicimos en el apartado previo, para analizar los formatos de acción hemos seleccionado las cuatro organizaciones más activas del ciclo, a saber: Barrios de Pie, Corriente Clasista y Combativa, Frente Popular Darío Santillán y Polo Obrero. Esta selección permitirá simplificar las tablas en las que se muestran los datos y, sin embargo,mostrar las características centrales del ciclo puesto que no existe ni una sola acción en la cual estos grupos no participen. Cabe decir, a modo de precaución, que estas organizaciones han realizado múltiples acciones en forma conjunta, por lo cual cada una de las acciones puede estar sobrerepresentada (por ejemplo, un bloqueo en el que participa la CCC y BdP está contabilizado en la columna de ambas organizaciones).

Tal como se puede observar en la tabla 4 el formato más utilizado es el corte de vías públicas. Este tipo de acción es el más importante en las cuatro organizaciones que contienen las mayores participaciones de este proceso de confrontación. Sin embargo, la envergadura de esta relevancia contiene matices.

Mirando en detalle esta tabla se puede observar que más del 60\% de las acciones desarrolladas por el FPDS en este período son bloqueos de vías públicas, presentando una diferencia de $45 \%$ respecto de la movilización, que es el formato de acción que aparece en segundo lugar. Esta primacía tan fuerte no se vislumbra en las demás organizaciones, pues si bien en las acciones de todas ellas el bloqueo es el tipo de acción colectiva más utilizada, la diferencia porcentual con respecto a la movilización se reduce a 6 puntos en el caso de BdP y a 8 puntos para el caso de $\mathrm{PO}$, notándose una mayor propensión a la realización de bloqueos en la CCC con $47,2 \%$ de las acciones y una diferencia en relación a las movilizaciones de 13 puntos porcentuales.

No obstante, tal como se desarrollará en el siguiente apartado, existe un salto entre el porcentual total y los porcentajes de las tres las organizaciones más importantes, en relación al peso de los cortes de ruta y, como contracara, el relativo descenso de las movilizaciones $(21,5 \%)$. Es en este sentido que se deben tomar en consideración a las organizaciones más chicas; fueron estas 15 organizaciones las que acompañadas por alguna/s de estas cuatro, fueron demarcando las características de este ciclo de confrontación instalando la central primacía del piquete. 
TABLA 4

Distribución de los formatos de acción. Principales organizaciones (primer período)

\begin{tabular}{|l|r|r|r|r|r|r|r|r|}
\hline $\begin{array}{c}\text { Formato de } \\
\text { acción }\end{array}$ & BdP & \multicolumn{1}{|c|}{$\%$} & CCC & $\%$ & FPDS & $\%$ & $\begin{array}{c}\text { Polo } \\
\text { Obrero }\end{array}$ & \multicolumn{1}{c|}{$\%$} \\
\hline Acampe & 5 & 7,35 & 7 & 12,96 & 3 & 6,25 & 3 & 7,89 \\
\hline Acuerdo & 2 & 2,94 & 0 & 0,00 & 3 & 6,25 & 1 & 2,63 \\
\hline Acto & 0 & 0,00 & 0 & 0,00 & 1 & 2,08 & 0 & 0,00 \\
\hline Anuncio & 5 & 7,35 & 2 & 3,70 & 1 & 2,08 & 3 & 7,89 \\
\hline Corte & 25 & 36,76 & 25 & 46,30 & 29 & 60,42 & 16 & 42,11 \\
\hline Movilización & 21 & 30,88 & 18 & 33,33 & 7 & 14,58 & 13 & 34,21 \\
\hline Ocupación & 2 & 2,94 & 0 & 0,00 & 2 & 4,17 & 0 & 0,00 \\
\hline Olla popular & 0 & 0,00 & 1 & 1,85 & 0 & 0,00 & 0 & 0,00 \\
\hline Petitorio & 2 & 2,94 & 1 & 1,85 & 1 & 2,08 & 1 & 2,63 \\
\hline Otro & 1 & 1,47 & 0 & 0,00 & 1 & 2,08 & 1 & 2,63 \\
\hline Sin datos & 5 & 7,35 & 0 & 0,00 & 0 & 0,00 & 0 & 0,00 \\
\hline Total & 68 & 100,00 & 54 & 100,00 & 48 & 100,00 & 38 & 100,00 \\
\hline
\end{tabular}

Fuente: PIP 11220110100563 Trabajo, redes territoriales y acción piquetera. El Impacto del Plan Argentina Trabaja (PRIST) en un movimiento de trabajadores desocupados del Gran Buenos Aires

A pesar de su escaso peso cuantitativo, consideramos que no se debe perder de vista la relevancia de los acampes. Tal como hemos desarrollado en un trabajo previo de tipo cualitativo (Maneiro, 2015), los 12 acampes producidos durante este período supusieron un corrimiento de las coordenadas témporo-espaciales de la ciudad, llevando la vida cotidiana de los barrios periféricos a las principales avenidas del centro porteño.

Para Laura, una cooperativista que participa en el movimiento, este aspecto aparece de la siguiente forma

Claro, habíamos hecho un acampe en la nueve de julio. Tres días. Yo me quedé a dormir un solo día porque tenía mis nenas... Y después estuve todo el día. Yo no me animé, pero hubo compañeras que se quedaron con los chicos, con el frío, y con la lluvia. Creo que llovió también...Y nada, pasamos hambre, porque hemos comido todos allá, pero no es fácil cocinar para todos, y no teníamos plata, y los chicos también, todo por reclamar entrar en un trabajo que debería ser para todos. O sea, no estábamos pidiendo que nos regalen nada, un trabajo... Y nos fuimos a quedar allá porque si no, no nos ven...(Laura FPDS-, comunicación personal, 22de octubre, 2012). ${ }^{31}$

Estos acampes fueron un formato de relevancia para la instalación del conflicto. El bloqueo de las principales avenidas por más de 24 horas corrompen profundamente la dinámica de movilidad de la ciudad aportando un componente cualitativo sin parangón que actualiza los largos acampes de la década de los 90, pero resituándolos en el centro mismo de la ciudad. La ciudad, entonces, ve el mundo doméstico de las familias, bajo el formato fotográfico de los medios de comunicación que, exponiendo sus grandes ollas populares -en un contexto de enfrentamiento con el gobierno nacional- exponen los pesares de los "pobres ciudadanos". ${ }^{32}$ 


\section{C) Las organizaciones participantes}

Ya hemos introducido en el texto que de este proceso movilizatorio participan diecinueve organizaciones. ${ }^{33}$ La amplia gama de participantes vuelve a poner de relieve un aspecto que había sido señalado en los momentos de génesis de estas organizaciones, identificando al movimiento de trabajadores desocupados como un movimiento de movimientos (Colectivo Situaciones, 2002). Un elemento no desdeñable a considerar en torno a esta extensa lista de participantes de las acciones es que las mismas se producen frecuentemente en acciones conjuntas, y es por ello que en la tabla 6 se podrán leer tanto los porcentajes de participación de cada organización, tomando como base el total de intervenciones de las organizaciones ( 507 participaciones), y el porcentaje de participación en las acciones, tomando como base la cantidad total de éstas últimas (163 acciones).

Cabe decir que, a pesar de que estas diecinueve organizaciones poseen una participación diferencial, existe una amplia gama de organizaciones con una participación significativa. Sólo seis de estas diecinueve poseen una participación menor al 10 por ciento de las acciones. De las trece que poseen más del 10\% encontramos que cuatro son las que presentan una frecuencia de participación que se distingue. ${ }^{34}$ La tabla 5 muestra la distribución de frecuencias de todos los grupos participantes durante el trascurso de este primer momento. 
TABLA 5

Frecuencia organizaciones participantes en acciones, porcentaje de participaciones y de acciones (primer período)

\begin{tabular}{|l|r|r|r|}
\hline Organizaciones & & $\%$ & $\begin{array}{r}\% \\
\text { Bacciones }\end{array}$ \\
\hline Barrios de Pie & 68 & 13,41 & 41,72 \\
\hline CCC & 54 & 10,65 & 33,13 \\
\hline FPDS & 48 & 9,47 & 29,45 \\
\hline Polo Obrero & 38 & 7,50 & 23,31 \\
\hline MTD AV/NvaFza & 37 & 7,30 & 22,70 \\
\hline MST Teresa Vive & 31 & 6,11 & 19,02 \\
\hline FOL & 29 & 5,72 & 17,79 \\
\hline FT26 de Julio & 28 & 5,52 & 17,18 \\
\hline MTL Rebelde & 26 & 5,13 & 15,95 \\
\hline MTR Democracia Directa & 25 & 4,93 & 15,34 \\
\hline Mov. Unidad y Lucha & 25 & 4,93 & 15,34 \\
\hline AT "Víctor Choque" & 24 & 4,73 & 14,72 \\
\hline FOB & 24 & 4,73 & 14,72 \\
\hline MTL & 15 & 2,96 & 9,20 \\
\hline Fogoneros & 14 & 2,76 & 8,59 \\
\hline CUBa-MTR & 10 & 1,97 & 6,13 \\
\hline Asambleas del Pueblo & 507 & 1,18 & 3,68 \\
\hline CTD-Quebracho & 25,59 & 1,84 \\
\hline MTR La Dignidad & 0,39 & 1,23 \\
\hline Total & 100,00 & \\
\hline
\end{tabular}

Fuente: PIP 11220110100563 Trabajo, redes territoriales y acción piquetera. El Impacto del Plan Argentina Trabaja (PRIST) en un movimiento de trabajadores desocupados del Gran Buenos Aires. Nota: 507 participaciones de organizaciones en las 163 acciones del período. 
GRÁFICO 2

Distribución cronológica de las participaciones de las cuatro organizaciones más activas

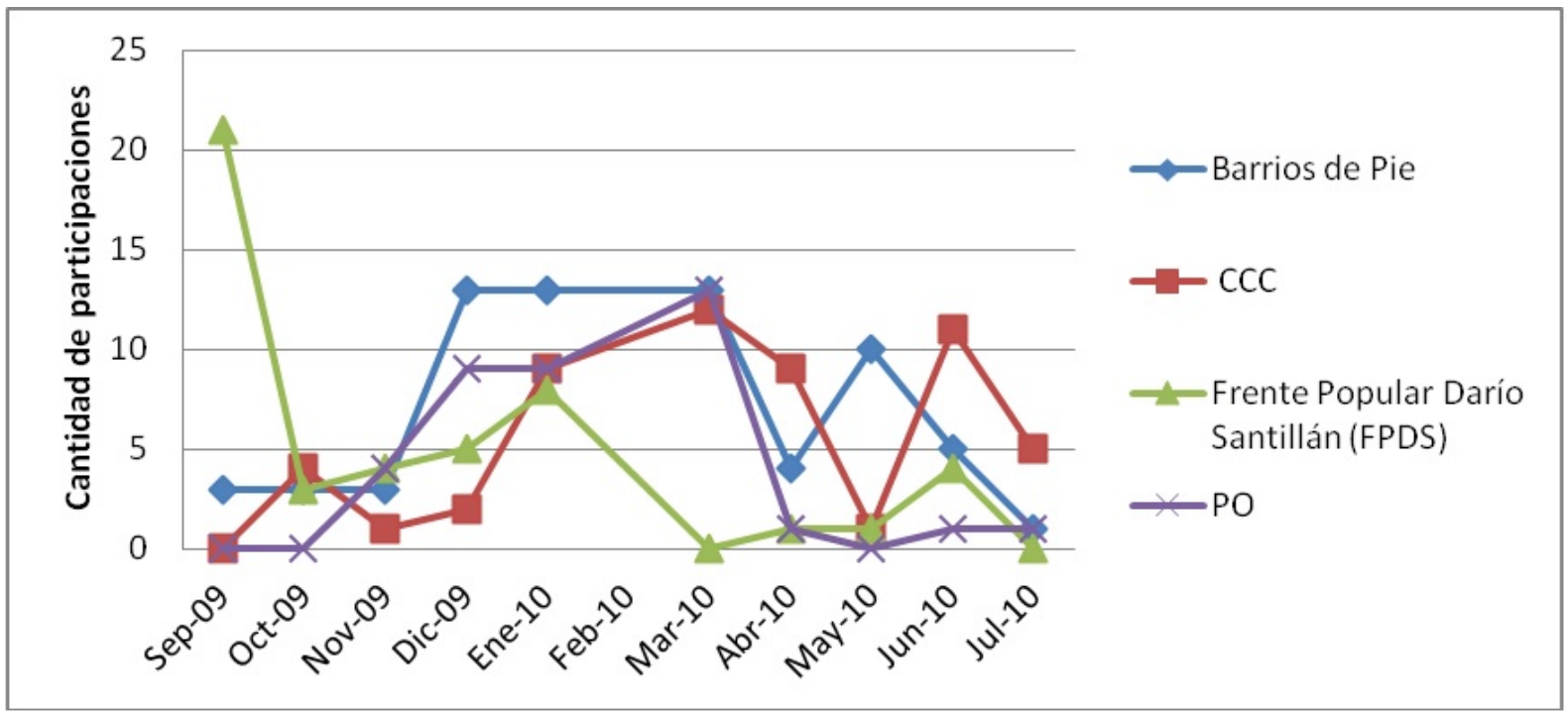

Tal como se puede ver en el gráfico 2, es evidente la centralidad del $\mathrm{BdP}^{35}$ en el proceso movilizatorio, no obstante un trabajo más profundo en torno a la temporalidad nos muestra que su participación más relevante se encuentra acotada en el tiempo, iniciando en diciembre y manteniendo en enero y febrero un enorme peso en las acciones de lucha, que se prolonga, aunque con desniveles hasta el mes de junio. La acción de esta organización es la que jalona el proceso en torno a figurarlo como una ojiva.

Un diseño temporal acotado, y con similitudes al de BdP se puede encontrar en el PO, que participa de las primeras acciones durante el mes de noviembre, pero concentra la mayor parte de sus protestas entre los meses de diciembre, enero, febrero y marzo.

El itinerario de la CCC es más extenso, sus primeras acciones se desarrollan durante el mes de octubre pero es recién en enero cuando ampliarán la cantidad de acciones hasta el mes de julio, inclusive -aunque con una pronunciada diminución en el mes de mayo, evidenciando la "tregua" del grupo en el marco de la conmemoración del bicentenario de la Revolución de Mayo-.

Este conjunto de organizaciones se encuentra sólidamente articulado en los meses de verano, comprobando la mayor confluencia durante el mes de marzo.

Por último el itinerario del FPDS presenta particularidades relevantes, pues casi la mitad de sus acciones de protesta se desarrollan durante el mes de septiembre, inaugurando el ciclo de lucha y emergiendo como el grupo de "los madrugadores" en este proceso. Sin embargo, y a pesar de participar de las acciones de los meses siguientes, su relevancia va perdiendo centralidad.

\section{D) Las redes de interacción}

Como se ha afirmado, de estas 163 acciones han participado diecinueve organizaciones. El promedio de participación por acción es de 3,1 organizaciones, lo que expresa un importante nivel de interacción.

Del listado total de participantes del proceso de confrontación hemos seleccionado aquellas cuatro cuya frecuencia las muestra en el centro de la escena: nos referimos a BdP, a la CCC, al FPDS y al PO. Como se puede ver en la tabla 5 , cada una de estas cuatro organizaciones participa de más del $20 \%$ de las acciones durante este primer momento.

Bajo el supuesto de que estas organizaciones, como ya se ha explorado en las dimensiones previas, se constituyen en articuladoras de las redes de acción, hemos de explorar las interacciones interorganizacionales. 
El interrogante que nos conduce propone visitar las redes de interacción que se expresan en el proceso de movilización. Esta exploración no ha resultado simple por la cantidad de organizaciones, acciones e interacciones que se encuentran en juego. Sin embargo, bajo la simplificación de ingresar a estas mediante la intersección con estas cuatro organizaciones mayores podemos abordar la hipótesis de que este proceso de confrontación yuxtapone y articula modalidades de (inter)acción que poseen especificidades. En este sentido, el diagrama 1 muestra todas las organizaciones participantes de este proceso de lucha, en una representación gráfica que muestra en escala su relevancia. En las elipses se encuentran las cuatro organizaciones con mayor frecuencia de acción y en escala el resto de las organizaciones. Las redes de interacción, asimismo, presentan líneas diversas según su nivel de articulación; estas refieren a las vinculaciones de todas las organizaciones participantes con estas cuatro que expresan una mayor frecuencia de aparición.

Como se puede ver, se descubren dos nodos con altos niveles de interacciones -sin que esto suponga la desarticulación total entre los dos ejes-. Uno de ellos contiene a las organizaciones sociales más grandes y con raíz político partidaria como Barrios de Pie, Polo Obrero y Movimiento Sin Trabajo Teresa Vive; entre ellas se descubre un alto nivel de interacción que evidencia la sistematicidad de las articulaciones en la acción.

Por otro lado, otra articulación fuerte se establece a partir del Frente Popular Darío Santillán que acciona el FOL, el MTD AV/NvaFza, el FT26 de Julio, la FOB, el MTL Rebelde, el MTR Democracia Directa, el Mov. Unidad y Lucha, la Asociación de Trabajadores Víctor Choque y Fogoneros. La amplitud de este arco es mayor al que se conforma en el otro eje. Asimismo, se vislumbran un conjunto de organizaciones con una participación escasa y con vínculos medianos y/o débiles con ambos núcleos de articulación, entre ellos cabe mencionar a CUBa-MTR y a las Asambleas del Pueblo. Por su parte la CTD-Quebracho presenta una articulación débil con el eje que articula el FPDS, y el MTL y el I MTR La Dignidad presentan articulaciones débiles con el PO. La relación entre ambos ejes parece sostenerse mediante una articulación sólida entre la CCC y el FPDS.

A partir de estos resultados se puede concluir que entre fines del año 2009 y comienzos del año 2010 se evidencian dos ejes movilizatorios de relevancia.Un eje contiene la mayor frecuencia de acciones y enlaza la línea político-partidaria con las organizaciones que durante los años de génesis de este movimiento de movimientos se articulaban con la línea sindical (BdP y la CCC); sin embargo, dentro de este entramado no se registra ninguna acción en la que participe la tradicional FTV que durante los gobiernos kirchneristas mantuvo una semántica movilizatoria no confrontativa respecto del gobierno nacional.

Un segundo eje de acción colectiva articulado a partir del FPDS congrega, centralmente, la línea territorial. Este conecta a las organizaciones sociales, muchas de ellas provenientes de escisiones y/o reorganizaciones con génesis en las organizaciones surgidas para mediados de los años 90 como MTD. Este conglomerado, a pesar de contener una menor frecuencia de acciones en su conjunto, contiene a una mayor cantidad de grupos, muchos de ellos de carácter local. Es este nucleamiento el que crea la AGTCAP, previamente mencionada. Consideramos que este nucleamiento constituye una de las innovaciones organizacionales del período pues pone en agenda pública la necesidad de conformación de una asociación gremial para los trabajadores autogestivos y precarios. Tal eje ha sido el que inicia este ciclo de protesta, para luego ir perdiendo fuerza ante la relevancia de las acciones del eje mencionado previamente.

Si bien en ambos ejes se vislumbra la primacía de las acciones con las tres demandas centrales, el reclamo de inclusión resulta el más ecuménico, mientras la demanda de nacionalización es más relevante en el primer grupo y la que refiere a la denuncia por uso clientelar es más significativa en el segundo; así se evidencian las particularidades de cada uno de estos entramados: uno más masivo y nacionalizado y otro más local y en puja con los referentes territoriales del espacio en el que se desempeñan.

Para terminar cabe decir que es el eje que aglutina a la línea territorial el que expresa una mayor propensión al uso del formato de bloqueos de vías públicas, actualizando una memoria de repertorio de lucha que fue constitutiva de la identidad de las organizaciones de raigambre territorial. Por el otro lado, el escalamiento interno dentro de las organizaciones que se articulan en la línea político-partidaria expresa las divergencias 
en las modalidades de acción colectiva, mostrando una mayor discordancia entre BdP y la CCC, esta última con una gran primacía de los bloqueos y la primera con una mucho menor propensión al uso de este formato de acción. Con todo cabe decir que durante este momento dicho formato de acción es el que prima, aunque con matices, en cada una de las organizaciones.

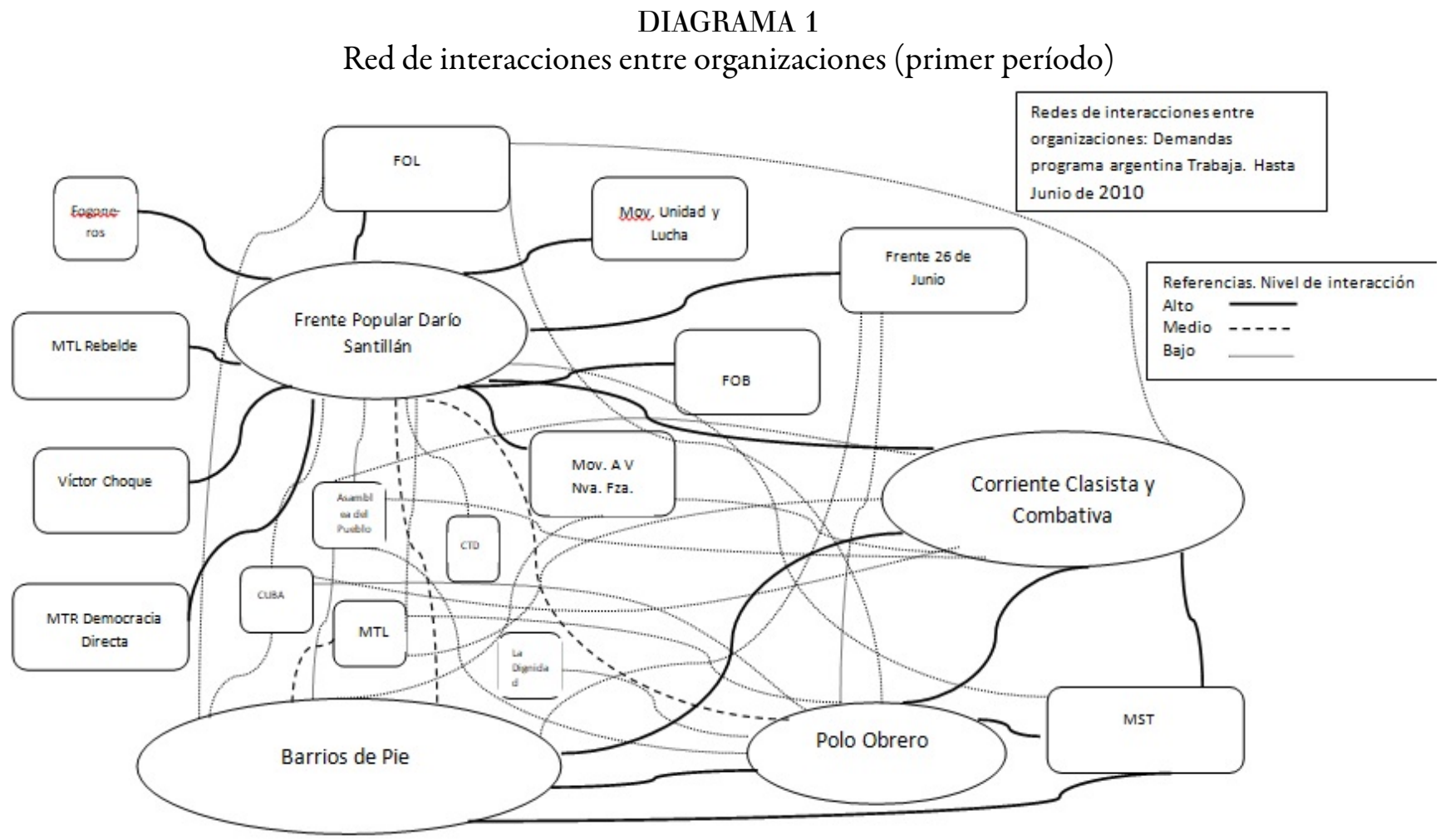

\section{ANALizando EL SEgundo MOMENTO}

Recapitulando las características generales de este segundo período de confrontaciones en torno al PRIST cabe señalar dos elementos: el primero es la mayor duración de esta fase y, el otro, la menor frecuencia mensual (densidad) de acciones de este momento.

El primer aspecto consideramos que se debe tanto a elementos que refieren al vínculo que se produce entre las organizaciones y el gobierno nacional del Estado en torno a la demanda de participación y gestión en programas de empleo, como a las características específicas que asume este programa. Asimismo, también es menester considerar la situación social, económica y política en la que se enmarca el ciclo. La primera cuestión se relaciona con el tipo de relación -precaria y presencial- que las organizaciones entablan con el gobierno del estado con los programas de empleo. ${ }^{36}$

La segunda cuestión se vincula con la característica central de esta fase que es el estancamiento nominal del monto del beneficio en un contexto inflacionario, y la tercera se refiere al contexto de ralentización de la economía, de amesetamiento de la capacidad de captación de trabajadores respecto del mercado laboral y a la expresión de una situación política menos favorable a la coalición de gobierno.

El otro punto a destacar es la menor densidad de acciones que presenta este momento. Cabe decir que durante esta fase el promedio mensual de acciones se encuentra en 6,2, lo cual, a pesar de su relevancia, supone una disminución considerable respecto de las más de catorce acciones mensuales del período anterior. Esta disminución cuantitativa, que puede verse en el gráfico 1, interpretamos que se relaciona con la diferencia cualitativa en torno a la especificidad de la fase; este período, si bien es heterogéneo, contiene como eje central de demandas, tal como se verá en el apartado que sigue, la puja referente a la retribución mensual 
recibida por los partícipes del programa. Entendemos que ésta constituye una demanda que se aproxima en forma sustituta- al requerimiento corporativo sindical; tal puja se expresa con otro nivel de combatividad y otra frecuencia, aunque con divergencias entre las organizaciones. Es en la yuxtaposición de este aspecto dominante, pero también en la permanencia de las demandas y formas de acción de la fase previa, que se produce la particularidad de este momento.

\section{A) Las demandas}

Adentrándonos nuevamente mediante las demandas en el período analizado, se debe subrayar que durante esta fase se observa una mayor dispersión de reclamos. Esto se debe a que se mantienen los pedidos de inclusión, nacionalización y la denuncia del uso clientelar del programa, pero con una frecuencia mucho menor a la que expresaban en el momento previo, mientras asume una significativa relevancia el reclamo por aumento del monto del ingreso. Las tres demandas preponderantes del período previo suman 125 apariciones, lo cual las iguala al reclamo de aumento del monto del programa que también aparece en 125 ocasiones. ${ }^{37} \mathrm{El}$ mantenimiento del pedido de expansión y apertura del programa en otras gestiones y territorios, así como la denuncia acerca de la modalidad clientelar de inclusión, remite tanto a los reclamos que continúan desde el proceso anterior, y que se ven enfatizados por la apertura gradual de las jurisdicciones provinciales, como así también a la negativa gubernamental respecto de la ampliación nacional del PRIST

La demanda de aumento del monto del ingreso -tal como se puede notar en la tabla 1- constituye un reclamo que aparece con mayor frecuencia en esta fase de confrontación. Vinculamos la relevancia de esta petición con la pérdida de valor del monto del ingreso, incluso en relación a otros ingresos laborales (y no laborales ${ }^{38}$ ) de las clases trabajadoras más empobrecidas. ${ }^{39}$

Con el objeto de mostrar esta pérdida de valor, en el gráfico 3 proponemos una comparación en torno al monto del ingreso del PRIST respecto del Salario Mínimo Vital y Móvil (SMVM). ${ }^{40}$ Como se observa en ese gráfico, el monto mensual del PRIST se mantiene estacionado durante 24 meses, lo que supone que el ingreso pase de significar el 85,67\% del SMVM en enero de 2010 a constituir el 55,87\% en agosto de $2011^{41}$ y, a pesar de la suba anunciada a fines de febrero de 2012 -implementada a partir de dos “incentivos", uno a la productividad y otro al presentismo-, la retribución no volvió a representar sino poco menos del $70 \%$ del SMVM durante ese año y el siguiente, para volver a decrecer significativamente en los años subsiguientes. 


\section{GRÁFICO 3:}

Comparación del monto mensual Programa "Argentina

Trabaja” y el Salario Mínimo Vital y Móvil en valores nominales.

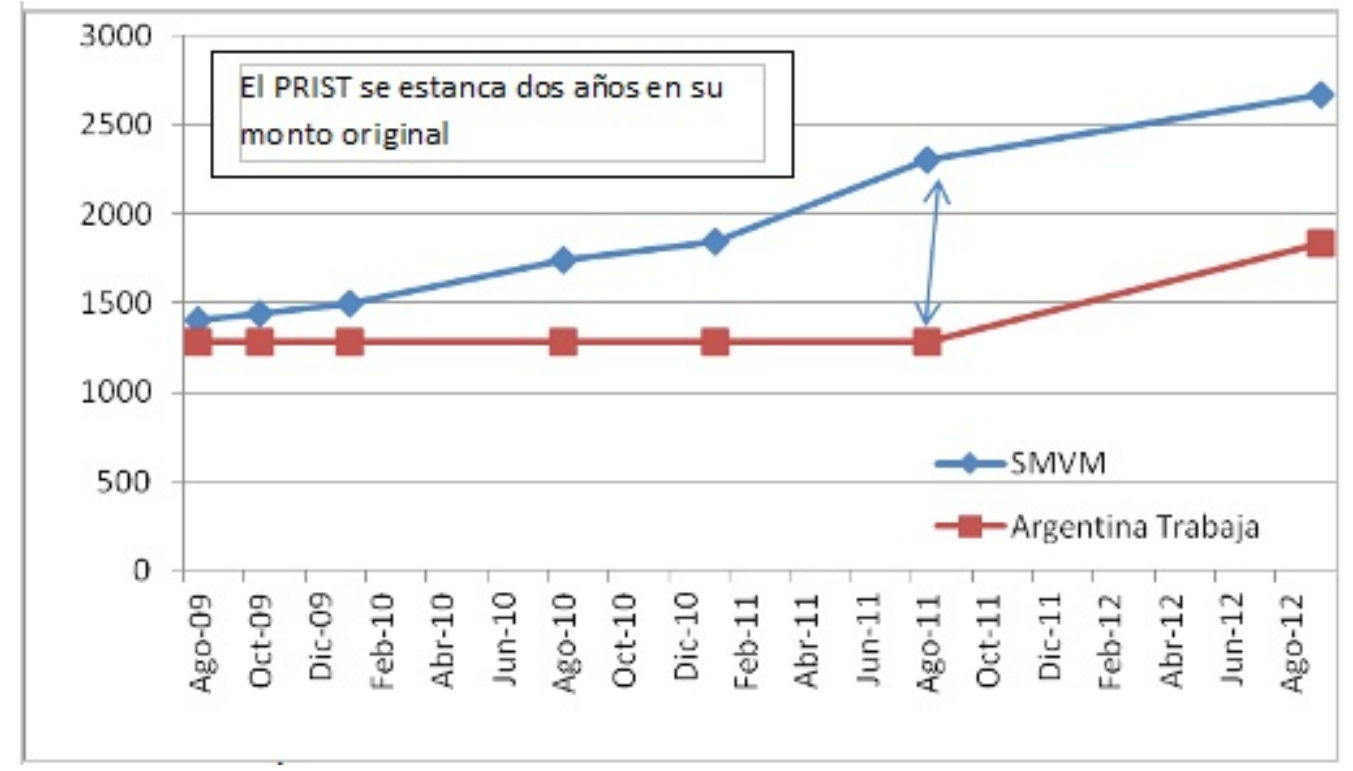

Elaboración propia a partir de documentos del Consejo del Salario y del Ministerio de Desarrollo Social.

Sin canales instituidos para la actualización del monto mensual del beneficio, el mecanismo de solicitud de su aumento se expresa -en estas organizaciones- en el recurso recurrente y sistemático de la acción colectiva. La precariedad de los recursos y la sistemática referencia a la presencialidad de lucha se expresa en este aspecto.

Ahora, cabría preguntarse - tal como lo hicimos en el análisis del período previo- cómo se distribuyen las demandas en las organizaciones partícipes. Antes de leer los datos cabe volver a enunciar la advertencia ya mencionada: se trata de acciones con demandas múltiples y de las cuales participan diversas organizaciones, con lo cual los datos hay que entenderlos bajo esta advertencia.

Dicho esto, es interesante notar, tal como se ve en la tabla 6, la prevalencia del reclamo de aumento del monto de retribución en casi todas las organizaciones. Esta relevancia posee un peso mucho mayor en BdP en relación a las demás organizaciones. Asimismo, en BdP se nota otra particularidad: casi el 20\% de las acciones demandan alimentos, pedido que no aparece en ninguna de las otras tres organizaciones mayores. La contracara de este diseño de demandas se puede ver en el FPDS, que además de perder iniciativa e importancia mantiene una mayor relevancia relativa de las tres demandas que caracterizaron el momento anterior. Estas tres demandas también mantienen una importancia relativa en la CCC y en el PO, organizaciones cuyo diseño demandante tiene semejanzas. 
TABLA 6

Distribución de las demandas. Principales organizaciones (segundo período)

\begin{tabular}{|l|r|r|r|r|r|r|r|r|}
\hline \multicolumn{1}{|c|}{ Demandas } & \multicolumn{1}{c|}{ BdP } & \multicolumn{1}{c|}{$\%$} & \multicolumn{1}{c|}{ CCC } & \multicolumn{1}{c|}{$\%$} & FPDS & \multicolumn{1}{c|}{$\%$} & PO & $\%$ \\
\hline Pedido de inclusión & 22 & 12,50 & 38 & 22,22 & 7 & 15,56 & 13 & 18,57 \\
\hline $\begin{array}{l}\text { Denuncia por uso } \\
\text { clientelar }\end{array}$ & 17 & 9,66 & 31 & 18,13 & 7 & 15,56 & 14 & 20,00 \\
\hline $\begin{array}{l}\text { Demanda de } \\
\text { nacionalización }\end{array}$ & 11 & 6,25 & 34 & 19,88 & 10 & 22,22 & 10 & 14,29 \\
\hline $\begin{array}{l}\text { Redamo de aumento de } \\
\text { "haber" }\end{array}$ & 71 & 40,34 & 43 & 25,15 & 10 & 22,22 & 20 & 28,57 \\
\hline Pedido de alimentos & 34 & 19,32 & 0 & 0,00 & 0 & 0,00 & 0 & 0,00 \\
\hline Otras & 21 & 11,93 & 25 & 14,62 & 11 & 24,44 & 13 & 18,57 \\
\hline Total & 176 & 100,00 & 171 & 100,00 & 45 & 100,00 & 70 & 100,00 \\
\hline
\end{tabular}

Fuente: PIP 11220110100563 Trabajo, redes territoriales y acción piquetera. El Impacto del Plan Argentina Trabaja (PRIST) en un movimiento de trabajadores desocupados del Gran Buenos Aires

\section{B) Los formatos de acción}

Observando la tabla 7 se puede ver que durante este segundo momento los dos formatos de acción más relevantes en términos cuantitativos continúan siendo los cortes y las movilizaciones e, inclusive, ambos sumados constituyen -aproximadamente- el mismo porcentaje de acciones que en el primer período; sin embargo la relevancia de cada uno de ellos se ha modificado. A pesar de que los bloqueos continúan constituyendo el formato más utilizado dentro del repertorio de estas organizaciones, su frecuencia disminuye casi 10 puntos en relación al momento próximo pasado, y lo contrario se constata en torno a las movilizaciones, ya que la frecuencia de ellas aumenta significativamente, ascendiendo ese mismo porcentaje. Esta evidencia muestra una sustitución parcial de un formato respecto del otro.

Como se ha mencionado con antelación, nuestro equipo realizó una serie de entrevistas a los militantespartícipes de una cooperativa del Frente Popular Darío Santillán. Para Laura, este aspecto aparece de la siguiente forma:

R: Hacemos marchas, que no es lo mismo la marcha que el piquete que es cortarte la ruta y no dejar pasar a nadie. Y marcha es marchar a Desarrollo y a diferentes puntos de lo que es acá, capital. Cuando ya es piquete, es porque ya estamos cansados de marchar y que no nos den bolilla. Y nos clavamos ahí. Mañana, es un ejemplo, mañana tenemos un corte. Y vamos a estar desde las ocho de la mañana hasta las seis de la tarde, para tratar de que alguien nos dé bolilla, para ver si podemos (...)

$\mathrm{E}: \mathrm{Y}$ ¿antes hacían más piquetes?

R: Sí. Sí, antes sí. Ahora con la cuestión de que tenemos la cooperativa, como que hemos bajado un poco, porque tenemos otras prioridades, otras cuestiones que hacer. Pero nunca se acaba. (...) La otra vez que fuimos a cortar el Pueyrredón (...) Pero hay cortes, se siguen haciendo. Y se hacen en simultáneo. Cuando por ejemplo, la otra vez se hizo para que las cooperativas sean ya a nivel nacional, se cortó acá, o sea, en capital, se cortó en Mendoza, en Chubut, en Tucumán y en Entre Ríos, creo que se cortó también. En todos esos lugares a la misma vez, a la misma hora y en el mismo día, en lo que es Desarrollo Social en todos los lugares. Y se coordina, se coordinan muchos cortes, para que esto siga, porque lo que es el Chaco... no hay cooperativas. Y sabemos que lo que es las provincias, sufren mucho el hambre (Laura-FPDS-, comunicación personal, 22 de octubre, 2012)..

En el relato de Laura aparecen dos elementos que hemos de resaltar. En este subyace una vinculación entre el tipo de demanda, el nivel de conflictividad y el formato de la acción. La demanda de inclusión -denuncia clientelar o nacionalización del programa- supone un nivel de confrontación más alto y se expresa en bloqueos, que a su vez son más duraderos y más potentes. Las demandas en torno a los montos u otros reclamos dentro del propio programa se efectúan mediante formatos de acción menos confrontativos: 
las movilizaciones. Asimismo dentro de su relato y tal como nos dirá Demetrio, otro entrevistado que luego aparecerá en este trabajo, la actividad cotidiana, tanto laboral como burocrática de la cooperativa, es identificada como un elemento que dificulta la realización de piquetes (que suponen mayores recursos de logística y una mayor disponibilidad de tiempo).

TABLA 7

Distribución de los formatos de acción. Principales organizaciones (segundo período)

\begin{tabular}{|l|r|r|l|r|r|r|r|r|}
\hline $\begin{array}{c}\text { Formato de } \\
\text { acción }\end{array}$ & ccc & \multicolumn{1}{|c|}{$\%$} & $\begin{array}{c}\text { Barrios } \\
\text { de pie }\end{array}$ & \multicolumn{1}{c|}{$\%$} & FPDS & $\%$ & $\begin{array}{c}\text { Polo } \\
\text { Obrero }\end{array}$ & \multicolumn{1}{c|}{$\%$} \\
\hline Acampe/vigilia & 2 & 3,28 & 1 & 1,12 & 0 & 0,00 & 0 & 0,00 \\
\hline Acto & 2 & 3,28 & 0 & 0,00 & 0 & 0,00 & 0 & 0,00 \\
\hline Anuncio & 0 & 0,00 & 3 & 3,37 & 0 & 0,00 & 1 & 4,35 \\
\hline Corte & 36 & 59,02 & 24 & 26,97 & 5 & 41,67 & 9 & 39,13 \\
\hline Movilización & 19 & 31,15 & 37 & 41,57 & 6 & 50,00 & 12 & 52,17 \\
\hline Olla popular & 0 & 0,00 & 1 & 1,12 & 0 & 0,00 & 0 & 0,00 \\
\hline Petitorio & 0 & 0,00 & 16 & 17,98 & 0 & 0,00 & 0 & 0,00 \\
\hline Otro & 2 & 3,28 & 7 & 7,87 & 1 & 8,33 & 1 & 4,35 \\
\hline Total & 61 & 100,00 & 89 & 100,00 & 12 & 100,00 & 23 & 100,00 \\
\hline
\end{tabular}

Fuente: PIP 11220110100563 Trabajo, redes territoriales y acción piquetera. El Impacto del Plan Argentina Trabaja (PRIST) en un movimiento de trabajadores desocupados del Gran Buenos Aires

Poniendo en relación los dichos de la entrevistada con los datos recabados en los medios de comunicación encontramos que entre las acciones de su organización los cortes perdieron peso respecto del periodo anterior ( 5 en este período sobre 29 en el período previo) y las movilizaciones, que fueron 7 en el período previo, constituyeron 6 en este período; sin embargo el principal elemento que caracteriza a este período respecto del FPDS es su menor participación general en las acciones de protesta. En este sentido, es central reconocer que el ingreso en el programa se vincula a una desmovilización de este grupo y de la estela de organizaciones que mantuvieron un estrecho vínculo con él.

En contrapunto, ingresando en cada una de las otras organizaciones que más acciones realizaron encontraremos magnitudes que expresan matices significativos. En primer lugar, los bloqueos continúan siendo el formato de acción más importante. Esta primacía de los bloqueos frente a las movilizaciones es primordialmente el resultado de la acción de la CCC. Casi el 60\% de las acciones de este grupo constituyen cortes, esta supremacía jalona la relevancia de este formato en todo este segundo período. Es en este sentido que entendemos que los dichos de nuestros entrevistados deben leerse dentro de una red de inteligibilidad en la que medien las tradiciones movilizatorias y los recursos de cada una de las organizaciones. ${ }^{42}$ Existe alguna posibilidad de que la hipótesis que presenta nuestra entrevistada en torno a la relación entre los bloqueos y la demanda de inclusión sea constatada en la CCC, pues como aparecía en la tabla anterior la relevancia de la demanda de inclusión, nacionalización y la denuncia del clientelismo mantienen gran importancia en esta organización. La extensión nacional de la CCC la lleva a ser la organización que más fuertemente reclama la nacionalización del programa, en sintonía con una modalidad de protesta más confrontativa. Sin embargo, tal como se mencionó anteriormente, al realizar acciones con demandas múltiples, también aparece entre los reclamos el pedido de actualización del monto del beneficio; este aspecto debilita una relación lineal entre una demanda y un formato -al menos en torno a esta organización-. 
La contracara de esta centralidad de los cortes se encuentra en BdP.En esta organización el bloqueo disminuye muy significativamente mientras asciende vigorosamente el uso de las movilizaciones e incluso se identifica -con relativa importancia- un formato menos confrontativo aún, sin movilización de cuerpos, como es el petitorio. Como se verá en el siguiente apartado la relevancia cuantitativa de las acciones de esta organización contribuye a la caracterización el período. Las memorias de acción de esta organización -que formó parte del entramado gubernamental poco tiempo atrás- pueden constituir un elemento a tomar en consideración para comprender la menor disrupción de sus acciones. No obstante una vez más los dichos de nuestros entrevistados conforman una lectura posible de los datos, pues la enorme relevancia de la petición de aumento de la retribución entre los reclamos de esta organización, como así también la demanda de alimentos, se asocian a otro tipo de formato de protesta menos confrontativo que los bloqueos.

La modalidad diferencial en torno a los formatos de acción de estas dos organizaciones centrales expresa uno de los elementos sobresalientes de esta fase.

Finalmente, en el PO la primacía de los bloqueos también se reduce, emergiendo las movilizaciones como el formato más importante de esta fase en un marco de transformación parcial del repertorio.

\section{C) Las organizaciones participantes}

La participación en este segundo período del ciclo analizado contrae algunas diferencias reveladoras respecto de la primera fase. Como se puede ver en la tabla 8, el primer aspecto a considerar es la disminución de los colectivos participantes. Si bien sólo dos de las diecinueve organizaciones previas no actúan en este segundo momento, trece lo hacen sólo con porcentajes menores al 10\%. Incluso el FPDS, que se encontraba entre las organizaciones más activas en el período anterior, tal como se ha mencionado en el apartado previo, retrocede significativamente en términos de capacidad de movilización. Una disminución relevante también se observa en el PO, cuya actividad no llega al $16 \%$ de las acciones. Una contra tendencia, relativa, en este proceso general de disminución del peso de las organizaciones no centrales es el sostenimiento en la participación del MST Teresa Vive -sustento que en términos relativos emerge como un aumento de su participación-. Este elemento, entendemos, se enlaza al aumento de la relevancia de sus aliados políticos.

El contrapunto respecto de esta evidencia es la centralización y la envergadura de las acciones en dos grandes organizaciones que adquieren una relevancia enorme: BdP y la CCC. Para comprender esta modificación resulta de interés comparar el porcentaje de participaciones que estas organizaciones tuvieron en el período previo, con el que conquistaron en esta segunda fase.Ambas reunidas, durante el primer momento de lucha, constituyeron el $24 \%$ de las participaciones, mientras que en este período sus participaciones ascendieron al 52\% del total de las mismas. Es menester recordar que si bien ambas habían tenido relevancia en el momento previo, esta centralidad no muestra parangón con la anterior y se relaciona de forma inversa con la disminución de las acciones del resto de las organizaciones y el declive de una de las redes de interacción mutua.

Retomando nuevamente el listado referente a todos los participantes, es primordial insistir en la disminución de la coproducción de las acciones de lucha, pues si en el período previo se evidenciaba una participación promedio de 3,1 organizaciones por acción, en este dicho promedio desciende a poco menos de 2 organizaciones por acción ( 144 acciones con 287 participaciones). 
TABLA 8

Frecuencia organizaciones participantes en acciones, porcentaje de participaciones y de acciones (segundo período)

\begin{tabular}{|l|r|r|r|}
\hline Organizaciones & Distribución & $\begin{array}{l}\text { \% de } \\
\text { participaciones }\end{array}$ & $\begin{array}{l}\text { \%de } \\
\text { acciones }\end{array}$ \\
\hline Barrios de Pie & 89 & 31,01 & 61,81 \\
\hline CCC & 61 & 21,25 & 42,36 \\
\hline FPDS & 12 & 4,18 & 8,33 \\
\hline Polo Obrero & 23 & 8,01 & 15,97 \\
\hline MTD AV/NvaFza & 5 & 1,74 & 3,47 \\
\hline MST Teresa Vive & 27 & 9,41 & 18,75 \\
\hline FOL & 8 & 2,79 & 5,56 \\
\hline FT26 de Julio & 6 & 2,09 & 4,17 \\
\hline MTL Rebelde & 8 & 2,79 & 5,56 \\
\hline MTR Democracia & & 1,74 & 3,47 \\
\hline Directa & 5 & 1,74 & 3,47 \\
\hline Mov. Unidad y & 5 & 2,79 & 5,56 \\
\hline Lucha & 6 & 3,14 & 6,25 \\
\hline AT "Víctor Choque" & 5 & 1,74 & 3,47 \\
\hline FOB & 5 & 1,74 & 3,47 \\
\hline Fogoneros & 5 & 1,74 & 3,47 \\
\hline CUBa-MTR & 5 & 4,17 \\
\hline CTD-Quebracho & 5,00 & \\
\hline MTR La Dignidad & & & \\
\hline Total & 5 & & \\
\hline
\end{tabular}

Fuente: PIP 11220110100563 Trabajo, redes territoriales y acción piquetera. El Impacto del Plan Argentina Trabaja (PRIST) en un movimiento de trabajadores desocupados del Gran Buenos Aires. Nota: 287 participaciones de organizaciones en 144 acciones del período.

\section{D) Las redes de interacción}

Tal como se puede observar, el diagrama 2 representa las redes de interacción de todas las organizaciones participantes con los cuatro grupos que expresan una mayor frecuencia de aparición. Ya una primera mirada muestra diferencias significativas respecto del primer momento estudiado. Un elemento central a considerar es la constatación de un solo nodo activo y dominante en el proceso de acción de lucha. La CCC y BdP son las organizaciones que articulan el eje de la acción en este período aunque también sobresalen el PO y el MST, evidenciándose entre ellos las articulaciones más sólidas. Cabe decir que el PO mantiene interacciones fuertes con ambas organizaciones, mientras que el MST Teresa Vive confluye más frecuentemente con la CCC. Todo 
esto permite inferir que $\mathrm{BdP}$, a pesar de que se articula débilmente con la mayoría de las organizaciones, ha priorizado -también- la acción beligerante, muchas veces, de manera autónoma.

Por último, es preciso señalar que el FPDS si bien sigue sosteniendo una red amplia de articulación su consistencia se ha debilitado significativamente. Las relaciones encontradas se caracterizan por la amplitud elemento que ya se evidenciaba en el momento previo-, pero durante este lapso prima la debilidad de los lazos de acción. Este aspecto fue señalado por Demetrio, un entrevistado que -dentro de un relato emparentado con Laura- afirma las dificultades de continuar movilizándose:

Depende mucho de la actitud de cada cooperativa, de cada movimiento cómo lo maneje. Porque desde el Gobierno lo mandan como un plan social, nada más; nos dan para que no salgamos más. Nos quieren sacar de la calle y, bueno, nos tiran todo esto. Mucha burocracia. Ahora, cada dos años cambian de cooperativa: otros papeles... Como que nos quieren tener entretenidos como para que no salgamos (Demetrio-FPDS-, comunicación personal, 18de septiembre, 2013). ${ }^{43}$

En el relato de Demetrio aparece que la búsqueda del FPDS es por trabajo, pero que lo que logran obtener son planes sociales; planes cuya gestión resulta dificultosa y requiere de tiempo. Para él es este el elemento central que fundamenta la dificultad del continuar la movilización. ${ }^{44}$

De la lectura de los resultados construidos a partir de los periódicos se puede afirmar que, desde mediados del año 2010 hasta mediados del año 2012, se debilita uno de los ejes movilizatorios de raigambre territorial que había inaugurado el ciclo de acción contenciosa que estamos analizando. Esta línea disminuye su frecuencia de acción, la cual se reduce a una asociación débil con las otras organizaciones más activas.

La tesis que aquí parece evidenciarse es que existe una vinculación entre el tamaño de la organización y la duración de la capacidad de movilización.Mientras las organizaciones más pequeñas y con anclaje territorial resultan centrales para abrir la contienda y construir nuevos procesos de lucha, son las de mayor escala las que logran sostener esta lucha en temporalidades más extendidas.

Por otro lado, se puede notar que las dos organizaciones que conformaban la línea sindical y que durante la génesis de estos movimientos se articulaban con la FTV - ahora ausente de este tipo de contiendas- asumen la primacía en la lucha, nos referimos a BdP y la CCC.

Ingresando en el seno de las organizaciones centrales que componen el eje más dinámico en este período, cabe decir que aunque entre las dos se manifiesta una articulación en la acción, los formatos que priman en cada una de ellas son diferentes. El bloqueo de vías públicas adquiere una enorme relevancia en la CCC, lo cual jalona los datos del período. En contrapunto, tanto BdP como las demás organizaciones utilizan mayoritariamente la movilización como formato preponderante de lucha. Este contrapunto entre estas dos organizaciones ya era visible en el primer período de lucha, pero se profundiza en este.

Finalmente queda decir que, aunque con matices, la afirmación que manifiestan los militantes en torno a la relación entre el formato de lucha y la demanda solicitada constituye una hipótesis que se verifica. Ellos vinculan las demandas de ingreso al programa, de denuncia del clientelismo y el pedido de nacionalización del PRIST con un formato de lucha más confrontativo que remite a los bloqueos, mientras entienden que la demanda de aumento de los montos del programa se enlaza con el formato de la movilización, expresando un nivel combativo menor. A pesar de la constatación general es menester ser prudentes pues la alusión a demandas múltiples en cada una de las acciones de protesta heterogeneiza el arco de estas últimas en cada uno de los formatos; asimismolas modalidades movilizatorias parcialmente diferenciales entre las organizaciones estudiadas remiten a memorias específicas de lucha y a recursos diferenciales que emergen como una variable de corte a tomar en consideración. 
DIAGRAMA 2

Red de interacciones entre organizaciones (segundo período)

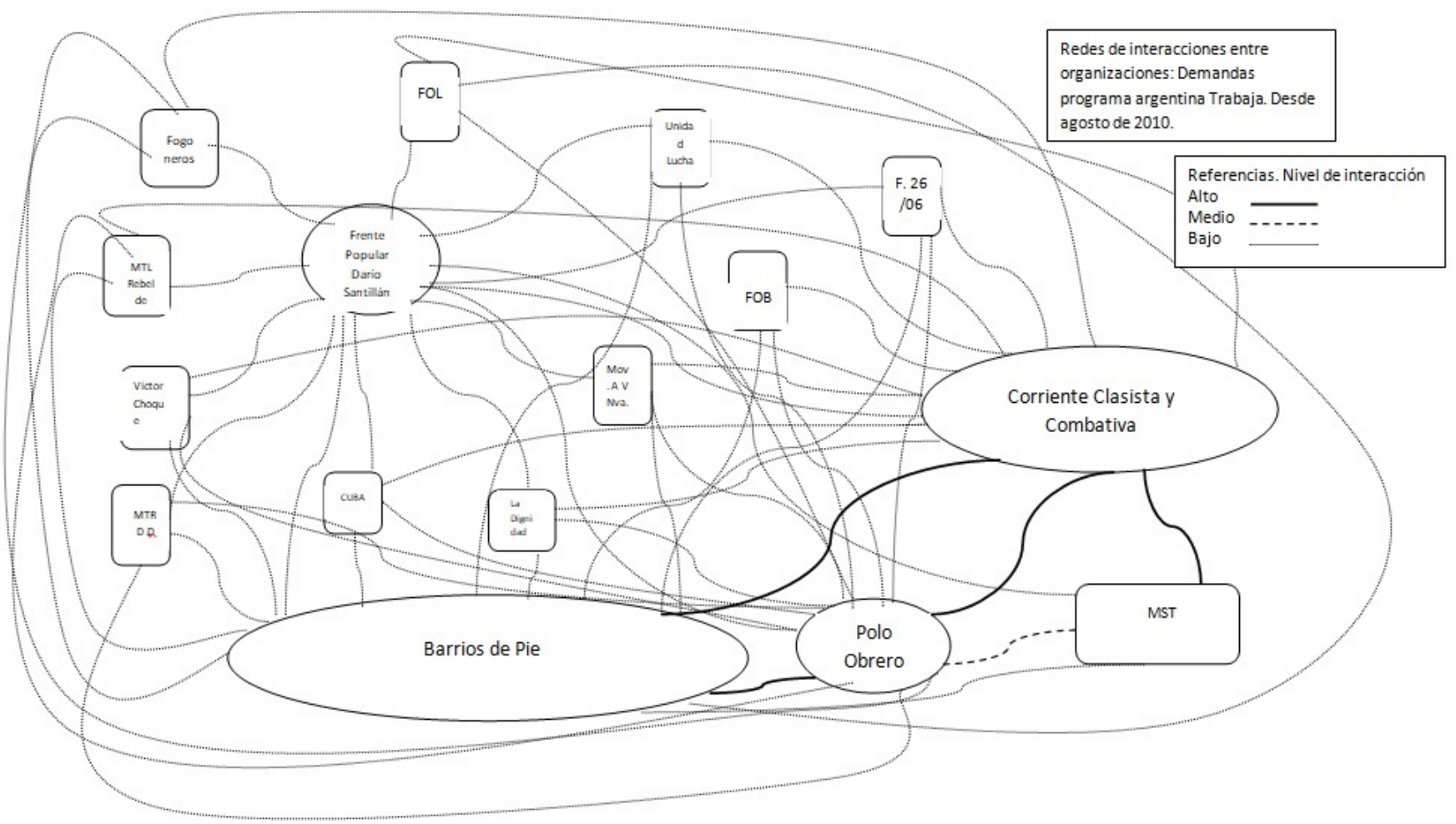

\section{Palabras finales}

Hasta hace diez años, los estudios en torno a la acción colectiva de las organizaciones de trabajadores desocupados irrumpían con gran ímpetu en el campo de estudios de las ciencias sociales. No obstante, durante los últimos años, el estudio de estas fracciones sociales se volcó más a la indagación respecto de sus tramas de interacción local y/o a las formas de articulación e intersección con las instituciones estatales.

El trabajo de investigación realizado se propuso mostrar empíricamente la emergencia de un nuevo ciclo en la acción de lucha de las organizaciones más desancladas respecto de la coalición de gobierno. En este, dichas organizaciones demandaban empleo a partir de su sucedáneo precario peticionando el ingreso y la ejecución del Programa Ingreso Social con Trabajo Argentina Trabaja.

Entendemos que esta emergencia pone de relieve dos elementos. Uno de ellos, ya analizado en los trabajos previos, es el tipo de relación - precaria y presencial- que las organizaciones entablan con el gobierno del Estado con el fin de defender su status legítimo de gestores de programas de empleo.

El otro aspecto remite al particular contexto en el que se produce este ciclo de acción y que se caracteriza por una situación política menos favorable a la coalición de gobierno, cuyo eje de tensión ha aparecido con el conflicto con las patronales del campo, pero cuya resonancia se expandió en torno a la posibilidad de movilización de otras fracciones sociales.

Asimismo, también resulta de importancia mencionar que todo este proceso se produce en un marco de ralentización de la economía y amesetamiento de la captación de trabajadores en el mercado laboral. Bajo este telón de fondo es que el gobierno anuncia una serie de medidas contra la pobreza. El anuncio del PRIST debe situarse en ese contexto.

Este trabajo permitió reconocer los momentos de acción beligerante, los sujetos que la producen, los tipos de acciones desarrolladas y las demandas requeridas. Asimismo se pudieron notar las transformaciones respecto de estas variables que se fueron suscitando en el ciclo mismo de acción. 
La investigación mostró la configuración de alineamientos diferenciales y articulaciones parciales en el "movimiento de movimientos" (Colectivo Situaciones, 2002) de trabajadores desocupados, y propuso una bisagra de estos hallazgos empíricos con la modalidad clasificatoria que ha elaborado uno de los estudios canónicos en torno a estos sujetos.

Los resultados construidos permitieron caracterizar dos momentos diferentes dentro del proceso de lucha relacionado al Programa Argentina Trabaja. Mientras durante el primer momento se constataron dos ejes dinámicos, uno ligado a las organizaciones de raigambre territorial y otro expresado por dos de las organizaciones que otrora conformaron la línea sindical -en forma articulada con la línea político partidaria-, el segundo momento mostró la debilidad y el eclipse del primer eje.

Asimismo, mientras el primer momento mostró una mayor amplitud y heterogeneidad en relación a las organizaciones partícipes, el segundo expresó mayor centralización en las dos organizaciones hegemónicas,BdP y la CCC. Es así como se expresa una asociación entre la capacidad de apertura del proceso de beligerancia y las organizaciones territoriales; son estas, bajo la articulación de la participación del FPDS, las que incluyen la demanda de participación en el PRIS dentro de la acción de lucha. Por otra parte, este trabajo expresa una articulación entre las organizaciones más masivas, sean estas de raigambre político partidaria y/o sindical, quienes evidencian una relevante capacidad para manteneren el tiempo la movilización. En este sentido consideramos que este trabajo colabora en la comprensión de la génesis de articulación y la relevancia de la articulación en la lucha entre la CCC y BdP.Estas tendrán un rol protagónico en confrontaciones posteriores, que están fuera del período analizado en este trabajo.

Cabe destacar que las demandas más importantes en cada uno de los períodos fueron distintas.Si durante el primer momento los ejes de solicitud se engarzaban a las demandas de inclusión en el programa, la denuncia de clientelismo y el pedido de nacionalización del PRIST, durante el segundo período, sin que se diluyan las demandas mencionadas, emerge con gran relevancia el pedido de actualización del monto del programa -lo cual se enlaza con la pérdida de valor del estipendio-.

Para terminar cabe decir que este estudio permitió reflexionar en torno a las vinculaciones entre determinadas demandas y formatos específicos. Según los militantes las movilizaciones se mostraron más frecuentes para las demandas de actualización del beneficio, y los bloqueos como modalidad de lucha para el reclamo de ingreso y expansión territorial del programa. Sin embargo, y matizando esta afirmación, en nuestro estudio hemos encontrado usos diferenciales de cada uno de los formatos que parecen estar más fuertemente vinculados con las tradiciones particulares de lucha de cada una de las organizaciones analizadas.

\section{BiBLIOGRAFÍA}

Argentina Trabaja. (2011). Ejecución del Programa: Principales resultados al primer trimestre de 2011. Buenos Aires: Ministerio de Desarrollo Social.

Auyero, J. (2001). La politica de los pobres. Buenos Aires: Manantial.

Colectivo Situaciones. (2002). La Hipótesis 891. Más allá de los piquetes. Buenos Aires: Ediciones de mano en mano.

D’Amico, V. y Pinedo, J. (2009). Debates y derivas en investigaciones sobre "los piqueteros". Una bitácora de lectura. Revista Sociohistórica, 25, 155-180.

Farías, A., Nardín, S. y Santana, G. (2013). Más que mil palabras: los Movimientos de Trabajadores Desocupados en el diario Clarín. Revista Mexicana de Sociología, 75, 465-499.

Ferraudi Curto, C. (2014). Las fronteras cambiantesentre lo político y lo social: aspectos etnográficos al debate en torno de "el 2001" en Argentina. Revista Sociohistórica, 34, s/n.

Frederic, S. (2004). Buenos vecinos, malos politicos: moralidad y politica en el Gran Buenos Aires. Buenos Aires: Prometeo. 
Gradín, A. (2016). La participación política de las organizaciones de desocupados en el Estado nacional durante el periodo 2003-2009. La experiencia del Movimiento Barrios de Pie: sus limites y potencialidades. Buenos Aires: Tesis Doctoral.

Gómez, M. (2006). Crisis y recomposición de la respuesta estatal a la acción colectiva desafiante en la Argentina 1989-2004. Revista Argentina de Sociologia , 6, 88-128.

Goren, N. (2005). "Plan Nacional Manos a la Obra". ¿Promoviendo el desarrollo local o asistiendo a la pobreza?.ASET. Disponible en https://www.aset.org.ar/congresos/7/13007.pdf

Guimenez, S. y Hopp.M. (2011). Programa ingreso social con trabajo "Argentina Trabaja”: una mirada reflexiva desde el corazón de su implementación. En A. Arias, A. Báselo, y B. García Godoy, Políticas públicas y Trabajo Social. Aportes para la reconstrucción de lo público. Buenos Aires: Espacio.

Iñigo Carrera, N., y Cotarelo, C. (2004). La insurrección espontánea. Argentina, diciembre 2001. Descripción, periodización, conceptualización. PIMSA 2003 , 201-308.

Lobato, M.y Suriano, J. (2003). La protesta social en Argentina. Buenos Aires: Fondo de Cultura Económica.

Longa, F. T. (2016). ¿Entre la autonomía y la disputa institucional? El dilema de los movimientos sociales ante el Estado. Los casos del Frente Popular Daría Santillán y el Movimiento Evita (Argentina, 2003-2015). Buenos Aires: Tesis Doctoral.

Maneiro, M. (2012). De encuentrosy desencuentros. Estado, gobiernos y movimientos de trabajadores desocupados. Buenos Aires: Biblos.

Maneiro, M. (2009). Las dos vías de la experiencia de los movimientos de trabajadores desocupados. En P. Lenguita, y J. Montes Cató, Resistencias Laborales (pp. 243-275). Buenos Aires: Insumisos Latinoamericanos- El Aleph.

Maneiro, M. (2015). Tiempos y espacios en disputa: Un modelo analítico para analizar la reaparición de las protestas urbanas de los movimientos de trabajadores desocupados. Quid 16, 151-169.

Maneiro, M., Farías, A., y Santana, G. (2009). Estudio del proceso de separación del problema de la desocupación de la acción piquetera . Revista de Conflicto Social, 1, 217-250.

Maneiro, M., Bertotti, C., Farías A., y Grance, E. (2015). Imágenes en movimiento. Buenos Aires: Editorial El colectivo.

Manzano, V. (2009). Un barrio. Diferentes grupos: Acerca de las dinámicas políticas locales en el distrito de La Matanza. En Grimson, A., Ferraudi Curto, C. y Segura, R. (comp.), La vida politica en los barrios populares de Buenos Aires. Buenos Aires: Prometeo.

Massetti, Á. (2011). Las tres transformaciones de la política pública asistencial y su relación con las organizaciones sociopolíticas (2003-2009). Entramados y Perspectivas, 1, 9-36.

Massetti, Á. (2004). Piqueteros. Protesta social e identidad colectiva. Buenos Aires: Editorial de las Ciencias. FLACSO.

Melucci, A. (1999). Acción colectiva, vida cotidiana y democracia. México: El Colegio de México.

Natalucci, A. (2012). Políticas sociales y discuputas territoriales. El caso del "Programa Argentina Trabaja". Revista Perspectivas de Politicas Públicas, 3, 26-147.

Natalucci, A., y Paschkes Ronis, M. (2011). Avatares en la implementación de políticas sociales. Concepciones y prácticas de las organizaciones sociopolíticas que participan en el Programa Argentina Trabaja (2009-2010). En A. Arias, A. Básalo, y B. García Godoy, Politicas públicas y Trabajo Social. Aportes para la reconstrucción de lo público. Buenos Aires: Espacio.

Perelmiter, L. (2016) La burocracia plebeya. La trastienda de la asistencia social en el Estado argentino. Buenos Aires: UNSAM.

Pereyra, S., Pérez, G., y Schuster, F. (2008). La huella piquetera. La Plata: Al Margen.

Pérez, G., y Natalucci, A. (2012). Vamos las bandas. Organizaciones y militancia kirchneristas. Buenos Aires: Nueva Trilce.

Quirós, J. (2006). Cruzando la Sarmiento. Una etnografia sobre piqueteros en la trama social del sur del Gran Buenos Aires. Buenos Aires: Antropofagia.

Repetto, F., Boix, M. V., y Fernández, J. P. (2011). Cómo fortalecer el “Argentina Trabaja”. Aprendizajes de Esteban Echeverría. Documento de Políticas Públicas. Recomendación N $95,1-15$. 
Retamozo, M. (2006). Los piqueteros: trabajo, subjetividad y acción colectiva en el movimiento de desocupados en Argentina. América Latina Hoy, 42, 109-128.

Schuster, F., Pérez, G., Pereyra, S., Armesto, M., Armelino, M., Analía,... Zipcioglu, P. (2006). Transformaciones de la protesta social en Argentina 1989-2003. En Documento de trabajo N 48. Buenos Aires: IIGG, Facultad de Ciencias Sociales, UBA.

Svampa, M., y Pereyra, S. (2003). Entre la ruta y el barrio. La experiencia de las organizaciones piqueteras. Buenos Aires: Biblos.

Tarrow, Sidney (1987), El poder en movimiento. Los movimientos sociales, la acción colectiva y la politica, Madrid, Alianza Editorial.

Tilly, Ch. y Wood, L. (2010) Los movimientos sociales 1768-2008. Desde sus origenes hasta Facebook. Barcelona: Crítica. Tilly, Ch. (1978). From Mobilization to Revolution. Londres: Mc. Graw Hill.

\section{Notas}

1 Entre muchos otros trabajos podemos mencionar a Gómez (2006); Iñigo Carrera y Cotarelo (2004); Retamozo (2006); Schuster y otros (2006); Svampa y Pereyra (2003).

2 Es importante mencionar que no todas las notas del corpus remiten a acciones de protesta: algunas refieren a opiniones, datos previos, contextualizaciones, recordatorios, etc. Estas noticias fueron relevantes para conocer más profundamente el nudo de sentidos en el cual se interpela el programa y la acción de las organizaciones. Sin embargo no forman parte de la base de datos final, que sólo remite a las acciones colectivas de demanda de ingreso y/o de ejecución del programa.

3 Cabe decir que una particularidad de nuestro estudio es que remite sólo a acciones de lucha sectoriales en demanda de ingreso y ejecución del PRIST.

4 Específicamente me refiero al proyecto PIP 11220110100563 “Trabajo, redes territoriales y acción piquetera. El Impacto del Plan Argentina Trabaja (PRIST) en un movimiento de trabajadores desocupados del Gran Buenos Aires” que dirigí y del cual participaron María Carla Bertotti, Ariel Farías, Guadalupe Santana y Santiago Nardín. Es menester decir que en la elaboración de la base de datos también trabajó Denise Kasparian.

5 Cada una de estas líneas ha tenido variaciones y desprendimientos. Retomaremos esta cuestión a lo largo del trabajo.

6 La relevancia de la dimensión territorial, incluso en estas organizaciones más extendidas espacialmente, pone de relieve la porosidad de las clasificaciones utilizadas.

7 Tanto la CCC, como BdP y el MTL constituyen organizaciones articuladas a una organización político-partidaria; este elemento muestra la doble pertenencia de las mismas y, una vez más, nos hace reflexionar sobre la falta de exhaustividad de las clasificaciones.

8 D'Amico y Pinedo (2009) proponen entender estas dos vertientes de los estudios sobre "los piqueteros" como aquellos estudios que abordan a las organizaciones como el núcleo de indagación,siendo por ello trabajos en torno de los piqueteros entendidos como actor colectivo, y los que estudian las tramas de sociabilidad en las que se insertan las organizaciones piqueteras -con sus intersecciones y fragmentaciones- dentro de una red de interacciones locales.

9 Una ventana de ingreso a estos trabajos y a su relevancia en el campo de investigaciones sobre "los piqueteros" se puede encontrar en el artículo de D’Amico y Pinedo (2009).

10 Cabe decir que esta corporación es la dueña del diario que ha servido de sustento empírico para la construcción de la base de datos con la que se desarrolla el presente artículo.

11 Esta cuestión fue trabajada por múltiples autores. Mi perspectiva en torno a este asunto se puede ver en Maneiro (2012).

12 La productividad de la acción colectiva respecto de la demanda de programas de este tipo fue constatada por los trabajos académicos (ver entre otros trabajos Gómez, 2006).

13 Este se crea en el ámbito de la Secretaría de Políticas Sociales bajo el nombre Plan Nacional de Desarrollo Local y economía social "Manos a la obra", bajo la resolución 1.375/04.Un interesante trabajo en torno al desarrollo de este programa y a la red de sujetos sociales participantes se puede ver en Goren (2005).

14 En relación a nuestra interpretación de esta política social ver Maneiro (2012). Otra perspectiva de interés se puede encontrar en el trabajo de Massetti (2011).

15 Este mapeo resume mi investigación previamente citada (2012).

16 Es importante aclarar que con esto no afirmamos que las organizaciones que se suman a la base política del gobierno se desmovilicen, pero sí que sus procesos movilizatorios asumen otros significados; por el otro lado, tampoco entendemos que las organizaciones opositoras al gobierno queden insertas en una relación de ajenidad absoluta respecto de la 
institución estatal, por el contrario, desde mediados de la década de los 90, todas estas organizaciones gestionan programas sociales y presentan niveles diferenciales de responsabilidad burocrática.

17 Este anuncio es contemporáneo al que introduce la Asignación Universal Por Hijo (AUH).

18 El discurso con el anuncio presidencial del PRIST se encuentra disponible en la web en: http://presidencia.gob.ar/inf ormacion/actividad-oficial/3551.

19 Una revisión de las características de este programa a la luz de sus predecesores se puede encontrar en Natalucci y PaschkesRonis (2011) y Guimenez y Hopp (2011) y en Natalucci (2012).

20 Tal como se verá en este trabajo, el monto del "beneficio" se estancó nominalmente y la demanda de actualización fue un elemento central de las acciones de protesta.

21 Más precisiones acerca de este programa pueden verse en mi trabajo (Maneiro, 2015).

22 Un trabajo reciente de Longa (2016) explora exhaustivamente las tensiones producidas en el seno del gobierno en torno a la forma de implementación de este programa y al estatuto de las municipalidades y sus referentes territoriales.

23 Esta entrevista fue realizada el día 14 de septiembre del año 2012 en el patio del local del Movimiento de Trabajadores Desocupados Javier Barrionuevo (integrante del Frente Popular Darío Santillán), en el Barrio Las Colinas de Esteban Echeverría. Con este movimiento, asimismo, realizamos un proyecto de extensión universitaria que dio como resultado el libro Imágenes en movimiento (Maneiro, Bertotti, Farías y Grance, 2015).

24 Alejandra fue nuestra primera entrevistada. El encuentro inaugural fue realizado el 26 de junio de 2009 en el Puente Pueyrredón en las actividades de conmemoración del asesinato de Maximiliano Kosteki y Darío Santillán. Esta entrevista es el fruto de un segundo encuentro que se llevó a cabo en la sede del Movimiento de Trabajadores Desocupados Javier Barrionuevo en el comedor de dicha institución el día 12 de mayo de 2010.

25 En un trabajo previo analizamos este primer momento con mayor profundidad y en él describimos esta situación que aquí mencionamos (Maneiro, 2015).

26 El término clientelar ha sido fuertemente tematizado por la bibliografía sobre politicidad popular. Entre las referencias obligadas se puede citar a Auyero (2001) y a Frederic (2004). En este artículo este término aparece como condensador de una demanda nativa que logra articularse con un sentido mediático. Los sentidos que se enlazan a este significante en cada uno de estos sectores tienen divergencias, pero se constituye un marco contextual que posibilita este enlace. Este aspecto fue parcialmente abordado en un trabajo previo (Maneiro, Farías y Santana, 2010).

27 Tal como se mostrará en el devenir del trabajo, la consigna "cooperativas sin punteros" es fundante del primer momento de este ciclo de acción colectiva y constituye un núcleo reivindicativo central en una de las redes de articulación que se constata en este proceso de confrontación. Esta red se solidifica con la creación de la AGTCAP (Asociación Gremial de los Trabajadores Cooperativistas Autogestivos y Precarizados).

28 Esta selección permitirá simplificar las tablas en las que se muestran los datos.

29 Un libro pionero respecto de la centralidad de este formato de lucha, como así también de la relevancia de estas organizaciones en el conflicto social, es el de Lobato y Suriano (2003).

30 Durante el año 2008 se produce un enfrentamiento que se dio en llamar el "conflicto del campo". Este polariza y generaliza una disputa entre las corporaciones de los propietarios de tierras contra el gobierno en torno al aumento de las retenciones arancelarias a las exportaciones. El formato de protesta que adoptaron los propietarios de tierras fueron los bloqueos de vías públicas; al referirse a ellos la Presidente Cristina Fernández de Kirchner los llamó "piquetes de la abundancia”.

31 Laura tiene 29 años y se desempeña como cooperativista y distribuidora de mercadería en la organización. Ella fue entrevistada en la sede del Movimiento de Trabajadores desocupados Javier Barrionuevo el día 22 de octubre del año 2012.

32 En torno a las imágenes mediáticas de este proceso de lucha se puede ver (Farías, Nardín, Santana, 2013).

33 Una breve descripción de cada una de ellas se puede encontrar en el anexo de este trabajo.

34 Si bien en este período el Polo Obrero posee una frecuencia muy cercana a la organización que le sigue, el MTD Nueva Fuerza, su primacía se acentúa en el segundo período.

35 Un excelente trabajo reciente de tesis resulta de interés para comprender el sinuoso proceso político de Barrios de Pie en estos períodos (Gradín, 2016).

36 Esta cuestión fue trabajada en mi libro (Maneiro, 2012).

37 Es relevante recordar que las demandas constituyen una variable con categorías no excluyentes, con lo cual se constatan 347 demandas en este período que, divididas en 144 acciones, revisten una media de 2,4 demandas por acción.

38 En una comparación respecto de la Asignación Universal por Hijo, realizada para una presentación en el Grupo sobre Participación y Movilización Política el 27/4/2016, también se constató la desvalorización relativa del PRIST.

39 Es sabido que existe un gap entre la existencia de una situación problemática y la emergencia de ello como demanda colectiva. Sin embargo, en procesos de activación movilizatoria, esta brecha puede ser atenuada. 
40 Entendemos que el valor del Salario Mínimo Vital y Móvil constituye un indicador que expresa el consenso, propiciado por el gobierno del estado, fruto de la negociación entre los representantes del capital y el trabajo acerca del valor mínimo indispensable para la reproducción de la fuerza de trabajo.

41 Aunque excede los límites temporales de este trabajo, cabe decir que esta proporción continuó disminuyendo.En enero de 2016 el monto del PRIST correspondía al 42,9\% del SMVM.

42 La noción de repertorio es usada por Tilly (1978) para listar, caracterizar y contabilizar los formatos de la acción. Sin embargo, existen otras dimensiones que frecuentemente quedan eclipsadas cuando se menciona este concepto; nos referimos al énfasis en las memorias actualizadas, los aprendizajes acumulados y las expectativas relacionales que se vinculan a la acción colectiva que elabora cada organización. La memoria de los procesos movilizatorios, el saber-hacer de cada formato de lucha fueron aprendizajes que se instalaron en la caja de herramientas de cada una de las organizaciones de trabajadores desocupados.

43 Demetrio tiene 54 años y es un trabajador informal que ha tejido diversas redes locales en el barrio; estas le posibilitaron trabajar, conseguir planes y/o mercadería, como así también tomar el terreno en el que vive. Hace pocos años, con el anuncio del PRIST, Demetrio llega al FPDS en el que realiza actualmente tareas cotidianas. La entrevista se realizó el 18 de septiembre del año 2013 en el Galpón del movimiento.

44 Este no podrá ser el lugar en el que analicemos los factores que se vinculan a esta pérdida de peso de las organizaciones que se configuran en torno al nodo que aglutina el FPDS. 